\title{
Review \\ Comparison of Prestressing Methods with CFRP and SMA Materials in Flexurally Strengthened RC Members
}

\author{
Janusz Rogowski *(D) and Renata Kotynia (D) \\ Department of Concrete Structures, Lodz University of Technology, Al. Politechniki 6, 93-590 Lodz, Poland; \\ renata.kotynia@p.lodz.pl \\ * Correspondence: janusz.rogowski@dokt.p.lodz.pl
}

\begin{abstract}
Over the years, prestressing concrete has become a well-known technique to improve the ultimate and serviceability state of RC members. Besides steel reinforcement, relatively new materials such as carbon fiber reinforced polymers (CFRP) or especially shape memory alloys (SMA) can be used to active strengthening. The main scope of this paper is to compare various prestressing methods using carbon composites and memory steel alloys. A description of SMA, shape memory effect, its utilization for prestressing, and CFRP materials are presented in the paper. Moreover, current stateof-the-art developments in the field of both materials, considering prestressing systems and available anchorage, material behavior, creep and stress relaxation, durability issues, thermal compatibility with concrete, and fire behavior, are described. A general revision of previous studies based on flexural strengthening using both materials is conducted and the selected results of these studies are briefly presented. The behavior of RC beams after strengthening with mentioned techniques is compared and discussed. Selected on-site applications are described to confirm the feasibility and practicality of the strengthening systems. Finally, the main advantages and disadvantages of CFRP and SMA materials for prestressing concrete structures are summarized and further recommendations for the future research are listed.
\end{abstract}

Keywords: prestressing; flexural strengthening; SMA; CFRP; RC beam; comparison

Citation: Rogowski, J.; Kotynia, R. Comparison of Prestressing Methods with CFRP and SMA Materials in Flexurally Strengthened RC Members. Materials 2022, 15, 1231. https:/ /doi.org/10.3390/ma15031231 Academic Editor: Łukasz Sadowski Received: 30 December 2021 Accepted: 2 February 2022 Published: 7 February 2022 Publisher's Note: MDPI stays neutral with regard to jurisdictional claims in published maps and institutional affiliations.

Copyright: (C) 2022 by the authors. Licensee MDPI, Basel, Switzerland. This article is an open access article distributed under the terms and conditions of the Creative Commons Attribution (CC BY) license (https:// creativecommons.org/licenses/by/ $4.0 /)$.

\section{Introduction}

Plenty of existing structures require retrofitting and strengthening. This is most often important due to the deterioration of structures, changes in using their functionality, or increasing design requirements. In the case of concrete structures in Poland, traditional methods of strengthening are still the most popular. These methods of retrofitting (with traditional materials such as concrete or steel) are well known and described by Al-Mahaidi et al. [1]. However, these techniques take up a lot of extra space, require unloading of the structure, and the strengthening efficiency will be significant after reloading. They are classified as passive strengthening techniques and do not affect significantly the serviceability limit state. To avoid these limitations, carbon fiber reinforced polymer (CFRP) composites have been used for over thirty years all over the world [2-5] and for over twenty years in Poland [6,7]. These materials exhibit great mechanical characteristics and high durability. A description of CFRP materials is presented in Section 3.

Strengthening with prestressed CFRP materials requires a mechanical anchorage that properly transfers prestressing force to the strengthened member to avoid debonding of composite material from the concrete surface. The anchorage systems are highly complex due to additional devices based on the hydraulic jacks, which are used for prestressing the CFRP laminates [8-11]. Due to the mentioned parameters, the overall costs of strengthening with CFRP materials increases significantly. The prestressing CFRP systems are described in detail in Section 4.1.

A promising alternative for the prestressing methods of existing concrete members, which substantially reduces these expenses, is prestressing using shape memory alloys 
(SMA). Several research studies about the most popular nickel-titanium based alloys (NiTiSMA), have been tested for decades and confirmed their capabilities for retrofitting concrete members $[12,13]$. However, these applications in the civil engineering industry have been limited due to their high material costs. Another type of SMA materials, based on iron and called FeSMA, with a reasonable production cost (in comparison to the NiTiSMA) has been developed for the last years and applied in 2009 [14]. More details referring to SMA materials are described in Section 2. These methods of strengthening concrete structures with prestressed CFRP and FeSMA gave promising opportunities not only for many existing structures but also for new structures. It seems reasonable that these methods should be compared in many studies. Hosseini et al. [15] conducted complex research for metallic structures. However, the number of research projects in this field is still limited for concrete structures.

This paper aims to present the current state-of-the-art developments in the topic of flexural strengthening of RC structures with prestressed SMA materials in comparison to that with CFRP. This comparison contains an analysis of materials behavior, available prestressing systems, and previous studies with applications of both memory steel and carbon composite materials. The paper provides a background for further research in this field which can be of significant interest.

\section{Description of Shape Memory Alloy Materials}

Shape memory alloys are metallic alloys (based on nickel, copper or iron) that have a unique property which allows them to return to their initial shape after having been permanently deformed. Examples of FeSMA materials are presented in Figure 1. The flexural strengthening of RC members with prestressed FeSMA strips has been widely tested in published research [16-18] and the first on-site Swiss application in carpentry used the FeSMA strips to the active strengthening of the RC slab [19]. Memory steel bars were embedded in a shotcrete layer [20] or applied as near-surface mounted reinforcement [21-24].

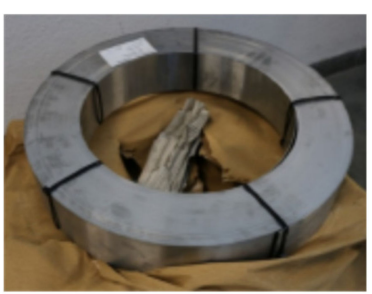

(a)

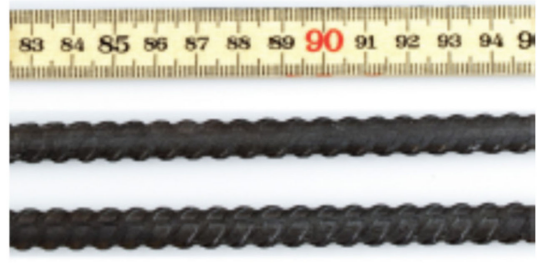

(b)

Figure 1. Iron-based shape memory alloy in the form of: (a) strips, reprinted with permission from ref. [18]. Copyright 2018 Elsevier; (b) bars, reprinted with permission from ref. [20]. Copyright 2016 Elsevier.

Change of deformability is called the shape memory effect (SME) and has to be activated by heating [18]. If the return to the initial shape occurs automatically by unloading, the effect is named superelasticity or pseudoelasticity $[13,25]$. SME is connected with (reversible) phase transformation of the lattice structure of the alloy [26]. It consists of a transformation between the austenitic state (high-temperature phase with a regular cubic crystal structure) and the martensitic state (low-temperature state with an irregular crystal structure) [21]. The first phase transformation is called a martensitic (or forward) transformation (FT) and appears when the material is cooled (in absence of stresses). The martensite begins to appear at the temperature, $\mathrm{M}_{\mathrm{s}}$, (martensite start) and the process finishes at the temperature, $\mathrm{M}_{\mathrm{f}}$ (martensite finish). The reverse transformation (RT) is induced by heating the material (in absence of stresses), begins at temperature known as, $A_{s}$, (austenite start) and has the end at the temperature, $A_{f}$, (austenite finish) [27]. These processes are presented in Figure 2. What is important is that they do not occur at the same temperature (thermal hysteresis takes place) [26]. 


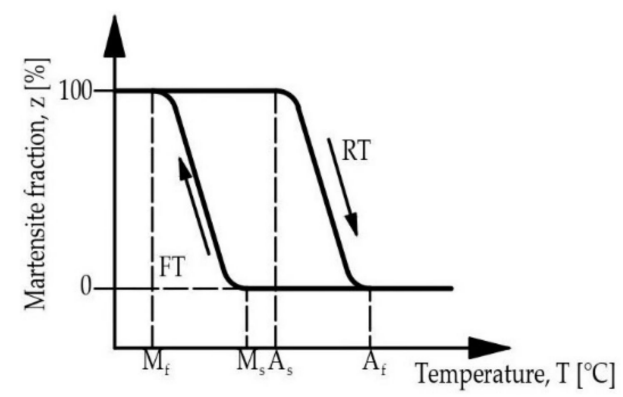

Figure 2. Temperature characteristics of the forward and reverse transformation (FT and RT, respectively), republished from [26].

Depending on the ambient and transformation temperatures profile of the alloy material, different phenomena occur in the material $[13,20]$. It can be assumed that the ambient temperature for outside applications is between $-20{ }^{\circ} \mathrm{C}$ (in winter) and $+60{ }^{\circ} \mathrm{C}$ (in case of strong solar radiation). Various kinds of SMAs can have significantly different transformation temperatures. These temperatures are not only related to the composition of the alloy but also the thermomechanical treatment during production [26,27]. Moreover, they may change if the material is under mechanical load, which is affected by a value and a way of loading [13].

Typical material phenomena and their associated temperatures profiles are presented in Figure 3. Alloys, for which martensite is a stable phase at ambient temperature, undergo pseudoplastic deformations if the yield strength is exceeded. If the temperature increases above $A_{s}$, the reverse transformation begins. As strain-stress curves for martensite and austenite are different, a change of stiffness takes place. An increase in the stiffness of the alloy causes the strain decreases against a constant force (Figure 3a). This phenomenon can be used for many applications (such as for actuators) [13].

Another property of the alloy, if martensite is the stable phase, is the ability to dissipate energy. This phenomenon is called martensitic damping and occurs when the material is subjected to cyclic loading (Figure 4a). A part of the energy can be dissipated due to a difference between the loading and unloading path (Figure 3d) [13].

If austenite is the stable phase at ambient temperature, external loading will induce martensite transformation (without change of temperature). The reverse transformation occurs automatically after unloading. This phenomenon is called superelasticity or pseudoelasticity and it exhibits some stress-strain hysteresis [27], as shown in Figure 3c. The amount of dissipated energy corresponds to the area between the loading and unloading path (see Figure $4 b$ [13]). More details about the damping properties of SMA can be found in other publications [28-30].

Permanently deformed alloys in the martensitic state can return to their initial shape after heating above the temperature $A_{f}$. This phenomenon is called the one-way shape memory effect or pseudoplasticity [13]. If the deformed material is restrained, some mechanical stress occurs after heating in the material (Figure 3b). In the beginning, due to the thermal expansion of the alloy, reduction of stress can be observed in Figure 5. However, the SME starts taking place after a certain temperature threshold. If the temperature grows to the peak temperature $T_{\max }$, tensile stress develops in the material. The stress obtained by cooling the specimen down is referred to as "recovery stress" ( $\sigma_{\text {rec }}$, see Figure 5$)$ and can be used for prestressing some elements of civil engineering structures [19].

The method of prestressing concrete structures using SMA reinforcements is shown in Figure 6. A strip, bar, or wire of SMA is prestrained (permanently elongated), then embedded (or mounted) in concrete. If the SMA reinforcement is heated (after curing of concrete) and its deformations are restrained, the recovery stress develops in the SMA. It causes some compressive stress to occur in the concrete. Different reinforced concrete members can be prestressed using this effect [31]. This method of prestressing does not require hydraulic jacks, ducts, or an anchor head. In the case of existing structures, it is sufficient to use end-anchorage (e.g., a direct fastening system) [32]. Moreover, the strongly 
curved structures can be also reinforced with this technique since no prestress force loss due to friction takes place [33].
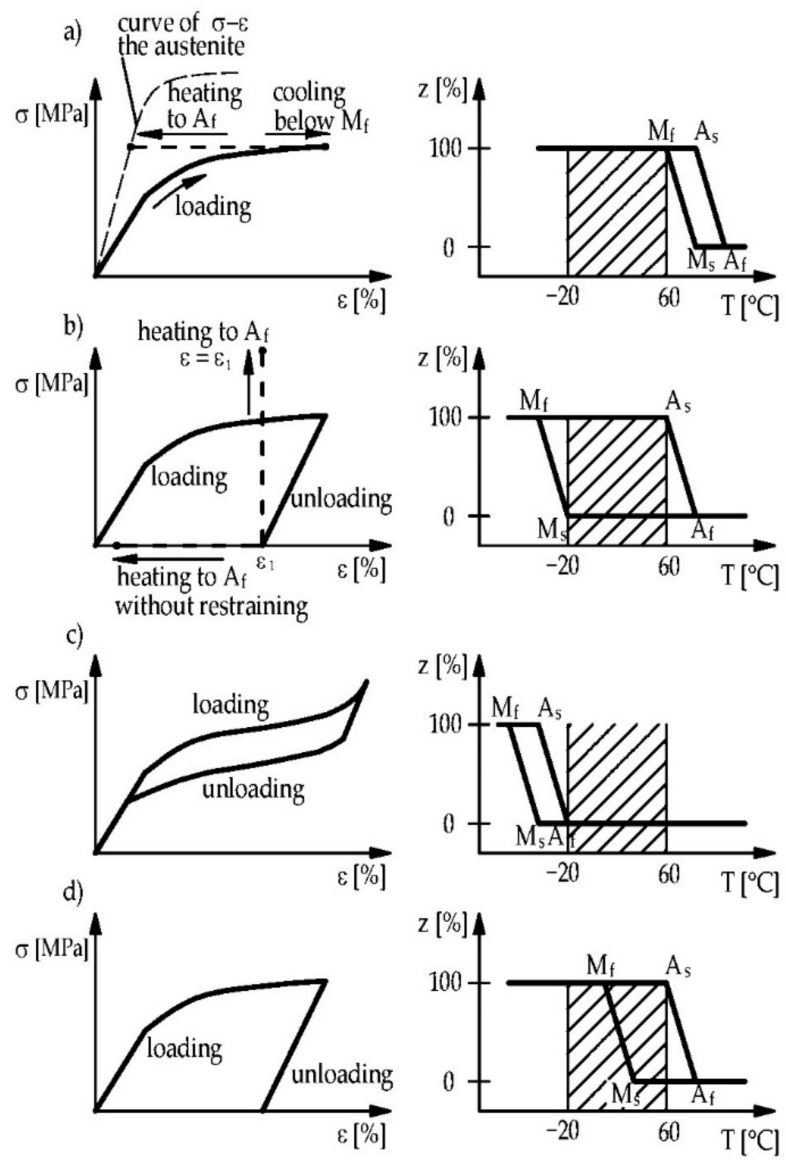

Figure 3. Stress-strain curves under loading (left) and transformation temperature profiles without loading (right): (a) strain and stiffness changes against a constant force; (b) shape memory effect; (c) superelasticity; (d) martensitic damping. Reprinted with permission from ref. [13]. Copyright 2005 Springer Nature.

a)

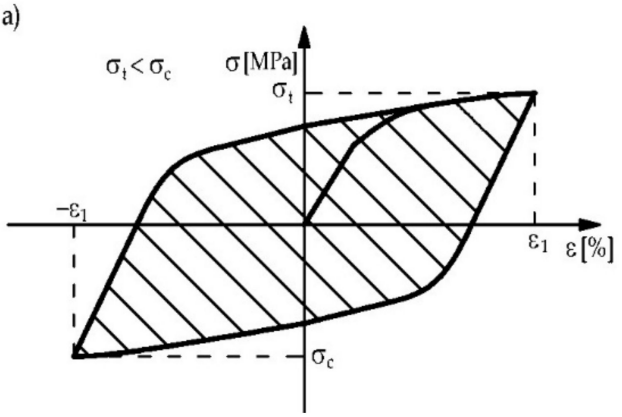

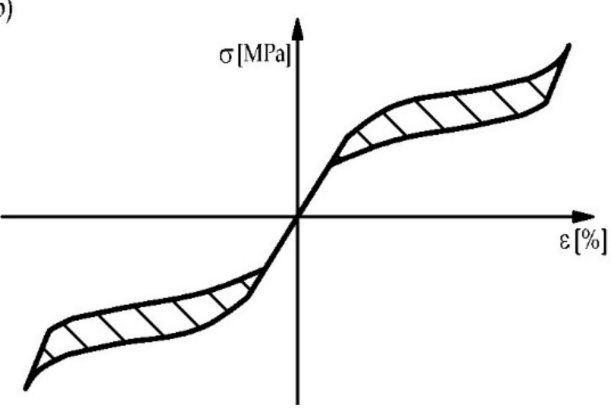

Figure 4. Stress-strain curve of alloy: (a) for stable martensite and cyclic loading and (b) for stable austenite and superelasticity alloy behavior (Reprinted with permission from ref. [13]. Copyright 2005 Springer Nature). 

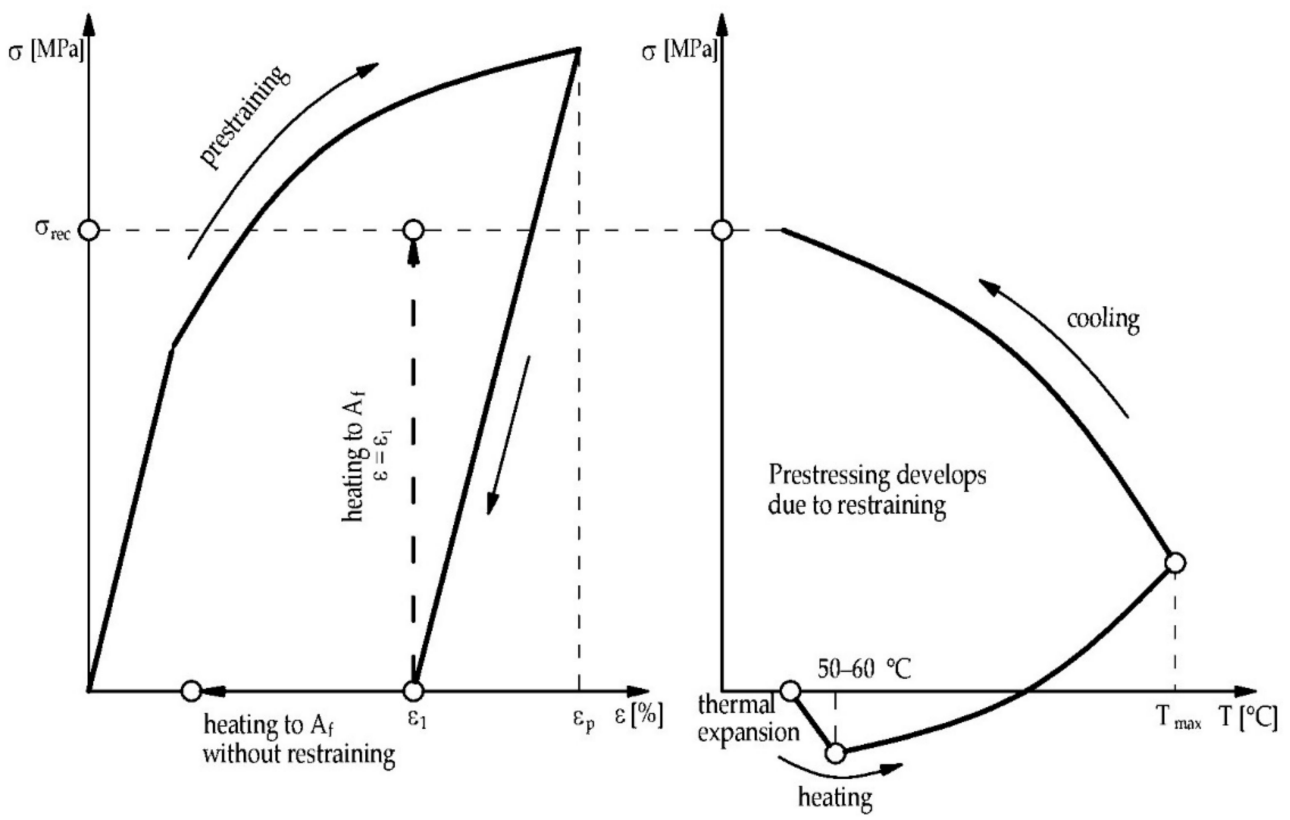

Figure 5. Characteristics of prestraining and activation SMA materials (Reprinted with permission from ref. [19]. Copyright 2018 John Wiley \& Sons-Books).

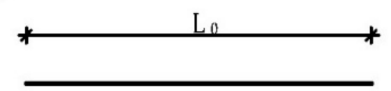

c)

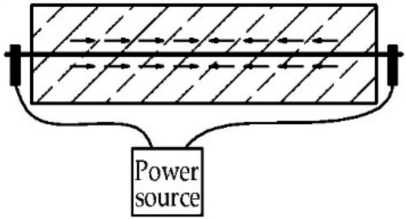

b)

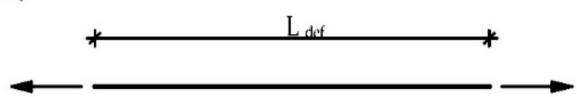

d)

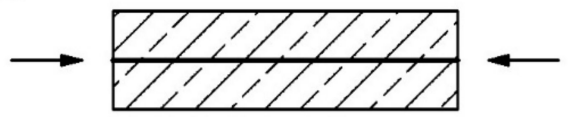

Figure 6. Scheme of prestressing of concrete member with SMA reinforcement: (a) initial SMA element with length $\mathrm{L}_{0}$; (b) prestrained element with length $\mathrm{L}_{\text {def }}$; (c) heating of the SMA, e.g., with electrical current; (d) concrete is prestressed, republished from [31].

\section{Description of Carbon Fiber Reinforced Polymers}

Fiber-reinforced polymers (FRPs) are composite materials composed of at least two components, namely fibers and a polymer matrix. The matrix performs the role of binder, distributes the uniform load, and protects the fibers against environmental effects [34]. The fibers have excellent mechanical properties and strength in tension, and therefore they are effective reinforcement materials [35]. From a structural point of view, the most promising material are carbon fibers (due to the highest value of Young modulus in comparison with other types of fibers) [34]. Hence, carbon fiber reinforced polymers (CFRPs) are selected to be compared with SMA and are briefly described in this section.

The properties of CFRPs depend on the volume of each component and the orientation of fibers. CFRPs are available for strengthening of civil engineering structures in the form of $[34,35]$ :

- Unidirectional pultruded laminates (strips)—Figure 7a,b;

- Sheet (with fibers in one direction) or fabrics (fibers are arranged in at least two directions) that are usually impregnated in-situ;

- Rods of bars that are made by pultrusion;

- $\quad$ Profiles (T-shape, L-shape)_Figure $7 \mathrm{~b}$. 


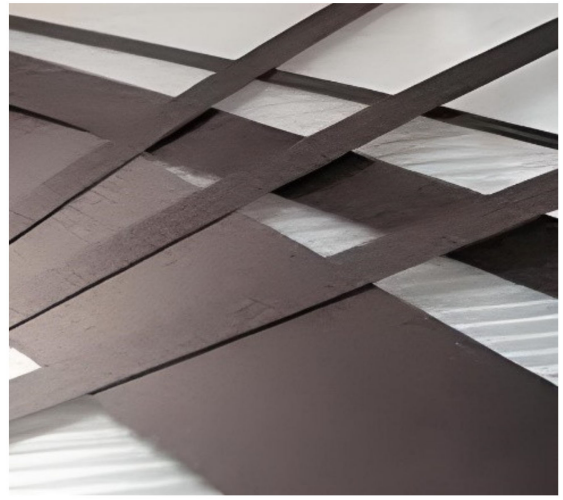

(a)

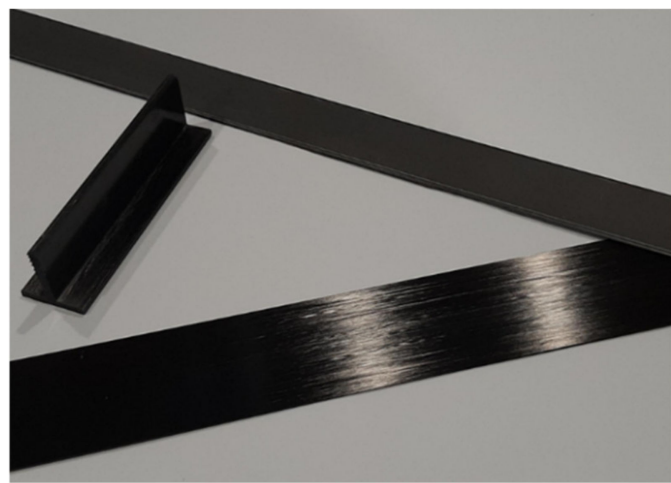

(b)

Figure 7. Examples of CFRP materials: (a) strips; (b) strips and T-shape profile.

The first application of CFRP materials was in the United States at the California Department of Transportation, Caltrans [36]. Application of CFRP materials for flexural strengthening of RC structures started in the 1980s at the Swiss Federal Laboratory for Materials Testing and Research (EMPA) [37,38]. Polish experiences in structural strengthening started from bridges with the first application of CFRP laminates in 1992 on the bridge over the Wiar river [39]. One year later, the second application with combined CFRP laminates and sheets was performed on the bridge over the Bystry canal [40]. Other Polish CFRP applications on the RC structures were published in $[6,10,41,42]$. Much more effective flexural strengthening with prestressed laminates was carried out in [7,43-47].

Most research and field applications on the flexural strengthening of RC members were carried out on simply supported beams and slabs strengthened on the bottom surface of the RC members without additional anchorage in the support region.

The existing research on reinforced concrete members flexurally strengthened with FRP materials can fail in several different ways, which are completely different in comparison with original RC members. There is a wide literature referring to classification of the failure modes published for the last two decades. The most common classification based on test results of the existing research was presented in [48]. Eight categories referring to material failure and interface debonding failure modes are summarized in Figure 8.

The most common failure mode is debonding of the FRP laminate from the concrete surface which may proceed as intermediate crack induced interfacial debonding (ICD) initiates at the flexural/flexural-shear cracks in the highest bending moment region (Figure 8f) and propagates by gradual debonding of the laminate from the flexural crack to the end of the FRP end (Figure 8f,g).

When debonding occurs at or near the end of a laminate it may proceed in three different ways:

- Critical diagonal crack (CDC) debonding occurs after the formation of a major shear crack intersecting the plate near its end and develops along with the laminate-concrete interface to the plate end (Figure 8b);

- $\quad$ Concrete cover separation (CCS) (Figure 8c);

- $\quad$ Plate end interfacial debonding (PEI) (Figure 8d).

Two additional failure modes refer to the FRP rupture and concrete crushing. However, the second one is possible only for the RC members of low concrete strength and high reinforcement ratio.

The effectiveness of the flexural strengthening depends on several factors including FRP type; axial stiffness and the number of CFRP layers; a distance of the CFRP end from the support; the existing longitudinal and shear steel reinforcement ratio; and bending moment distribution. Although EBR CFRPs increase the load-bearing capacity of an RC member, they do not significantly change the cracking load and deflections under the service loads. To gain the greatest advantage of the EBR technique, CFRP prestressing has 
been proposed to improve the serviceability of strengthened structures in order to reduce crack widths effectively, to relieve stress in the internal reinforcement, to enable control the crack distribution, limit deflection, and to increase the stiffness and the load capacity of RC members.

a)

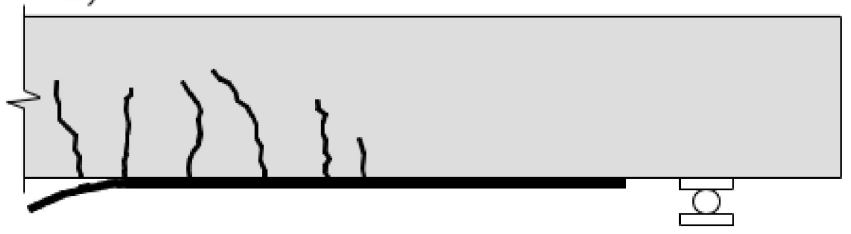

c)

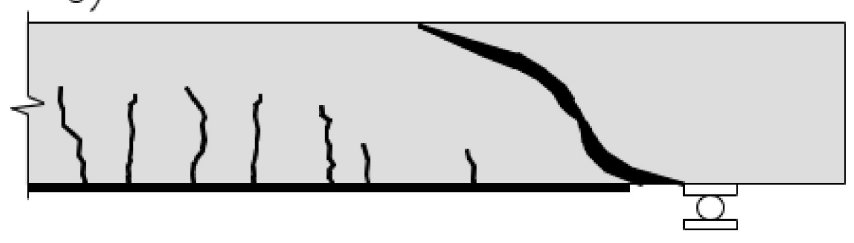

e1)

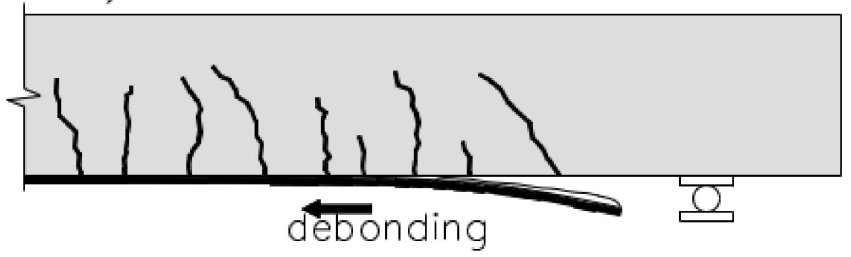

f)

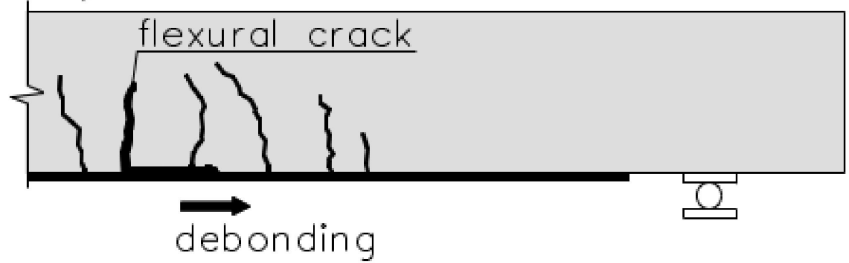

b)

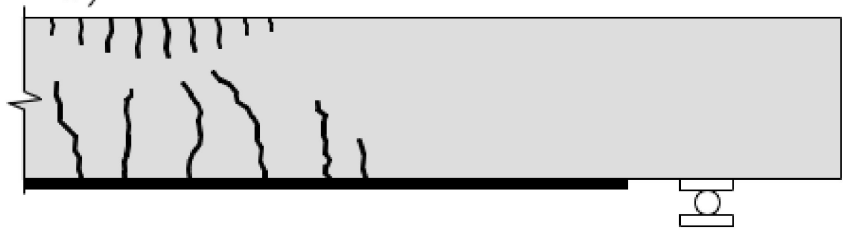

d)

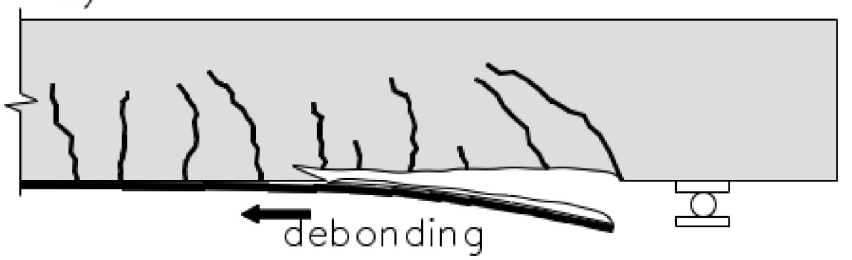

e2)

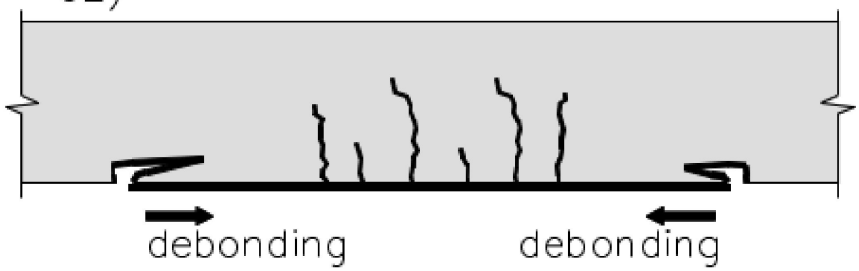

g)

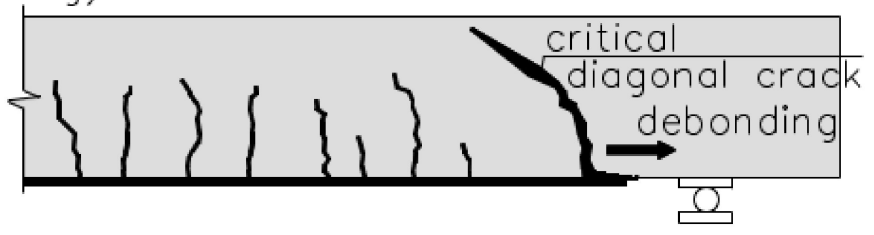

Figure 8. Failure modes of FRP-plated RC beams: (a) FRP rupture (R); (b) concrete crushing (CC); (c) shear failure; (d) concrete cover separation (CCS); (e1) plate end interfacial debonding (PE); (e2) plate end debonding in too short laminates; (f) intermediate flexural/shear crack-induced interfacial debonding (IC); (g) critical diagonal shear crack-induced debonding (CDC), Reprinted with permission from ref. [49]. Copyright 2002 Elsevier.

\section{Comparison of Prestressed FeSMA and CFRP Behavior}

This section is focused on a comparison of CFRP and SMA behavior and techniques of their applications to the strengthening of RC structures. The important parameters considered in this analysis contain tensile strength, Young's modulus, creep and relaxation, thermal compatibility, durability, behavior at elevated temperatures, prestressing procedure, prestressing force, and anchorage systems.

Memory steel based on iron has reasonable production cost, higher elastic modulus, and lower activation temperature in comparison with other types of SMA materials [50]. FeSMA materials described in Section 1 are chosen as a promising alternative for prestressing instead of CFRP materials.

\subsection{Prestressing and Anchorage Systems}

The state-of-the-art strengthening with prestressed FRP materials was published in $[9,34,51-53]$. Three main CFRP prestressing techniques were published in [9]: 
- Externally applied reinforcement (EAR) which include both externally bonded reinforcement (EBR) and unbonded reinforcement (without adhesive between composite and concrete); the unbonded reinforcement system is much less popular, but the applications can be found in [47,54];

- $\quad$ Near-surface mounted reinforcement (NSMR) [55-61];

- Externally post-tensioned (EPT).

In the EAR technique, CFRP reinforcement is in most cases prestressed to reduce existing deflections and to extend the flexural capacity of the existing concrete structures (direct prestressing method [53]). CFRP prestressing requires using a hydraulic jack which must be initially fixated on the concrete surface. In most cases, these elements are temporarily mounted and after strengthening they are removed [52]. The majority of CFRP prestressing systems requires also mechanical anchorage (MA) at both CFRP ends. Various types of MA systems have been investigated over the years and have been summarized in [8]. The most popular prestressing and anchorage commercially available systems have been developed by: S\&P Clever Reinforcement Company AG, Seewen, Switzerland [62]; "LeobaCarboDur" system by Leonhardt, Andrä und Partner, Stuttgart, Germany [63]; "Stresshead" system by Sika Bau AG, Zurich, Switzerland and Stress Head AG, Luzern, Switzerland [54]; "gradient—anchored" prestressing system by [64-66]; TENROC "gradient—anchored" prestressing system by Tenroc Technologies, Gothenburg, Sweden [67]; Polish Neoxe Prestressing System [46] and NPS II [43] by Neoxe, Cracow, Poland. Several noncommercial systems were used in the research: multi-layer CFRP sheets technique [55,68]; mechanically anchored, CFRP anchored U-wraps sheets [51,69]. Prestressing of CFRP materials maximizes the utilization of composites, excluding brittle failure modes caused by debonding $[70,71]$. For this reason, the system of strengthening with pretensioned laminates requires mechanical anchorage of their ends in the concrete surface [72].

In most cases, the MA systems are based on anchor plates. A direct prestressing system consists of the passive anchorage (dead end), while the second end is the active one [53,72] which can be additionally combined with the tensioning device [11]. The only non-mechanical anchorage system known as the "gradient-anchorage" (GA) was developed by Meier at EMPA [64,66] with the first field application in Poland [73]. The study on different anchorage systems published by Correira et al. [74] indicated that the MA system prevented premature debonding failure.

Reinforced concrete beams strengthened with prestressed CFRP laminates show three groups of failure modes: under-reinforced RC members failed due to FRP rupture $(\mathrm{R})$; over-reinforced RC members with composite reinforcement applied excessively, resulting in concrete crushing (CC). However, this failure mode is possible only for the RC members characterized by low concrete strength and high reinforcement ratio; intermediate crack induced by interfacial debonding (ICD), which initiates at the flexural/flexural-shear cracks in the highest bending moment region and propagates by gradual debonding of the laminate from the flexural crack to the FRP end and the group of RC members with the reinforcement not anchored sufficiently, in which leads debonding of FRP ends (plate end debonding (PE), concrete cover separation (CCS), anchorage failure (AF)) published in $[48,64,66,72,75-78]$.

The parameters affecting strengthening efficiency with externally bonded FRP prestressed materials contain type of FRP material (laminate, sheet); FRP stiffness; existing flexural tensile reinforcement ratio; existing shear reinforcement ratio; stiffness of the strengthened RC member (slab, beam); the size of the strengthened RC member; type of strengthening system (mechanically anchored, fully efficient (FRP rupture) or partially efficient (FRP sliding from the anchored system) and preloading level.

The flexural strengthening of RC members strengthened with pretensioned NSM FRP stirps or bars confirms the much higher efficiency of this technique compared to the passive strengthening. The main effect of pretensioning is based on the higher utilization of the tensile strength of the FRP materials, which contributes to the higher load-bearing capacity under service and ultimate load [55-57]. The effectiveness of the NSM method significantly depends 
on several factors including pretensioning level, cross-section and stiffness of FRP materials, and internal steel reinforcement ratio. Prestressing leads to an increase of the load-carrying capacity at concrete cracking and steel yielding; reduction of dead load deflections; reduction of cracks; and increase in the shear capacity by longitudinal prestressing [58-61].

The prestressing procedure for all types of SMA reinforcement is quite similar and it does not require using the hydraulic jacks. In the beginning, the SMA materials are initially prestrained at room temperature, and then the reinforcement (with permanent deformation) is applied and fixed to the concrete surface and the activation of the alloy is conducted by heating to the required temperature. The heat supply can be provided by infrared heating, electrical resistive heating [79] or using a gas burning torch [21]. Due to restraining the recovery stress develops in the SMA material (see Section 4.3). The restraining mechanism depends on the type of SMA and the strengthening technique [79]:

- For externally applied strips, the direct fastening system is used [80]. This method is based on the pre-drilling of the SMA strip to the concrete substrate and installation of the nails in the holes using powder-activated tools $[19,79]$;

- The NSM strips or bars can be inserted into the concrete grooves which are filled with cement-based grout [17,24,81]. The bars can be also fixed using end-anchors [21,82];

- The NSM bars can be also embedded in the shotcrete layer [20,24].

\subsection{Comparison of CFRP and SMA Tensile Behaviour, Creep and Relaxation}

FeSMA materials exhibit a similar stress-strain response as steel. The memory steel properties are affected by the alloy composite and the thermomechanical treatment during the production process [26]. In general, they have the higher ultimate strength (680-1000 MPa) and comparable or slightly higher ductility (ultimate tensile strain equal to $16-50 \%$ ) to the steel $[18,83]$. They are isotropic materials in contrast to composites, which are fully anisotropic with various tensile characteristics in different directions [34]. The properties of composites materials depend on fibers, matrix type and volume fraction. The CFRP materials have three times higher tensile strength than FeSMAs but they exhibit ten times lower ductility in the ultimate tensile strain compared with FeSMA materials [84]. The mechanical properties of the chosen iron-based SMAs, CFRP strips and steel are summarized in Table 1 and presented in Figure 9a.

Table 1. Characteristics of FeSMAs [18,26,83], prefabricated CFRP strips [84] and steel.

\begin{tabular}{cccc}
\hline Material & $\mathbf{E}_{\mathbf{S M A} / \mathbf{E}_{\mathbf{f}} / \mathrm{E}_{\mathbf{s}}(\mathbf{G P a})}$ & $\mathbf{f}_{\mathbf{S M A} / \mathbf{f}_{\mathbf{f}} / \mathbf{f}_{\mathbf{s}}(\mathbf{M P a})}$ & $\varepsilon_{\mathbf{S M A} / \varepsilon_{\mathbf{f}} / \varepsilon_{\mathbf{s}}(\mathbf{\%})}$ \\
\hline FeSMAs & $160-170$ & $680-1000$ & $16-50$ \\
\hline Low modulus CFRP strips & 170 & 2800 & 1.6 \\
High modulus CFRP strips & 300 & 1300 & 0.5 \\
\hline Steel & 200 & 600 & 25
\end{tabular}

$\mathrm{E}_{\mathrm{SMA}}, \mathrm{E}_{\mathrm{f}}, \mathrm{E}_{\mathrm{s}}$ : elasticity modulus of SMA and CFRP materials and steel; $\mathrm{f}_{\mathrm{SMA}}, \mathrm{f}_{\mathrm{f}}, \mathrm{f}_{\mathrm{s}}$ : tensile strength of SMA and CFRP materials and steel; $\varepsilon_{\mathrm{SMA}}, \varepsilon_{\mathrm{f}}, \varepsilon_{\mathrm{s}}$ : ultimate tensile strain of SMA and CFRP materials and steel.

The initial elastic modulus of FeSMA is similar to low modulus CFRP and is lower than steel and the high modulus CFRP strips. It should be mentioned that Young's modulus of the alloy depends on its actual state, which is about two times lower for the material after activation, $E_{a c t}$, than for the material in elastic state, $E_{\text {init }}$, see Figure 9b [18]. The behavior of SMA during unloading is nonlinear. A pseudoelastic strain is defined as the strain deviation from the linear elastic behavior and is presented in Figure 9b [18].

The creep behavior of FRP materials was investigated by Goertzen et al. [85] in the tensile creep research. No failure due to creep rupture was observed in the short-term $(1600 \mathrm{~h})$ at loads up to $77 \%$ of the ultimate tensile strength. The extrapolation of these data indicated that the tensile failure did not occur during a reasonable lifetime at the load corresponding to $65 \%$ of the tensile CFRP strength [85]. Hence, it is recommended to limit the prestressing level of carbon composites to $65 \%$ of the ultimate strength [86]. A 
negligible creep of the CFRP materials was confirmed in the studies $[87,88]$ referring to CFRP rebars [89], sheets [87], and tendons [90], which demonstrated no significant stress relaxation in the long-term behavior of the CFRP composites. Prestress losses in the RC members strengthened with prestressed CFRP occurs in the first $100 \mathrm{~h}$ while a further decrease in the prestressing stress is negligible [91].
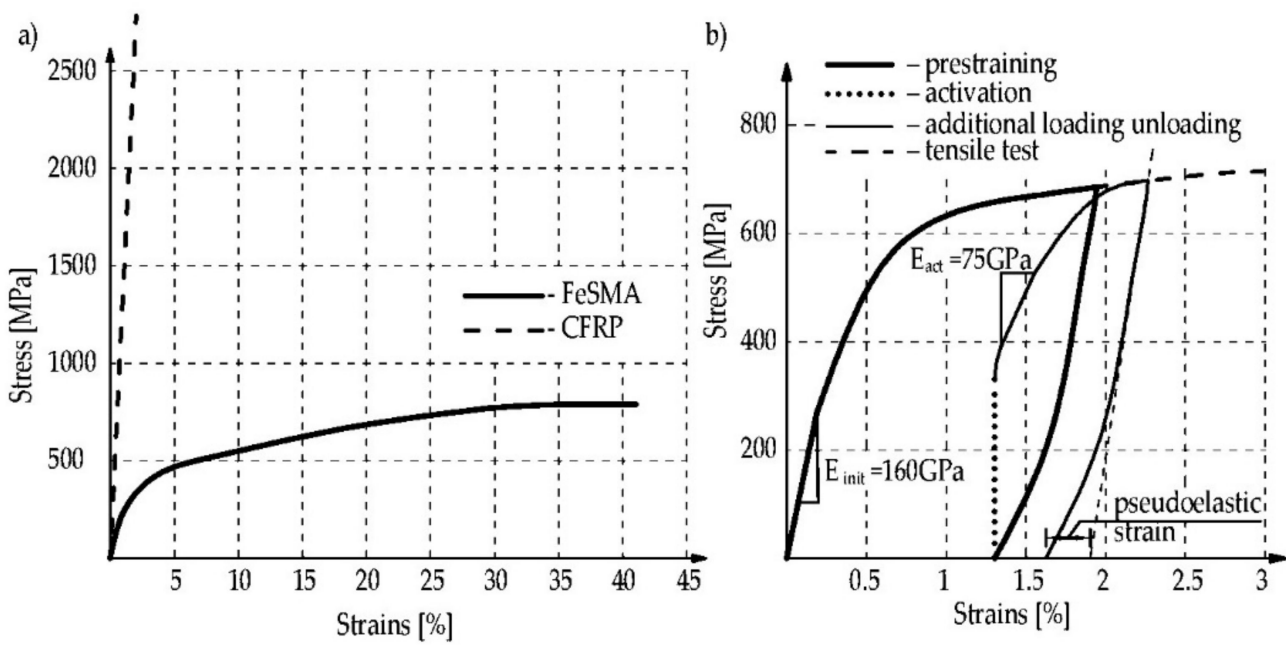

Figure 9. Stress-strain curves of FeSMA and CFRP materials: (a) under loading; (b) behavior of FeSMA at various stages (Reprinted with permission from ref. [18]. Copyright 2018 Elsevier).

A mount of tests referring to FeSMA relaxation has been carried out over the last years published in [18,92-96]. Both the stress relaxation at the constant strain and creep at the constant stress occurred in the SMA material. The study conducted by Leinenbach et al. [96] indicated that the creep strain was an order of magnitude higher than that for the high strength steels or Titanium (Ti) alloys. Moreover, for the temperature in the range from $-45^{\circ} \mathrm{C}$ to $50{ }^{\circ} \mathrm{C}$, the creep and relaxation are greater with the temperature drop (see Figure 10) [96]. A recovery stress decrease equal to $10 \%$ and $20 \%$ was observed after $1000 \mathrm{~h}$ in $[18,93,94]$, respectively. The greater prestress losses were affected by the SMA slip in the anchorage, temperature fluctuations and the live traffic loads. However, the total relaxation losses during the life cycle of the building can be estimated at 15\% [15]. It should be mentioned that the second (or multiple) activations (re-heated to the activation temperature and cooled to the ambient temperature) of SMA can retrieve a significant part of the prestressing losses [95].

\subsection{Achievable Prestressing Force}

The prestressing force in the SMA technique depends on the recovery stress of the alloy which is obtained after activation. It highly depends on the alloy composition, thermomechanical training, level of prestraining, and activation temperature. Based on data from research conducted by Cladera et al. [26], it has been indicated that recovery stresses for different Fe-Mn-Si alloys (with various thermo-mechanical training) are in the range of 130-580 MPa. The tests conducted by Shahverdi et al. [18] indicated that the higher recovery stress can be reached by increasing the maximal temperature during activation (more phase transformation is induced by higher temperature). The recovery stress of 356, 389, and $445 \mathrm{MPa}$ were obtained at the temperature of 177,190 , and $380^{\circ} \mathrm{C}$, respectively. It should be taken into account that the high temperature inside the concrete may lead to deteriorating its mechanical properties [26]. The recovery stress also increased with increasing the initial prestraining level with the plateau at $2 \%$ of prestraining. Based on the research published by Shahverdi et al. $[18,97]$ it was indicated the optimal level of prestraining (at a temperature of $160^{\circ} \mathrm{C}$ ). 

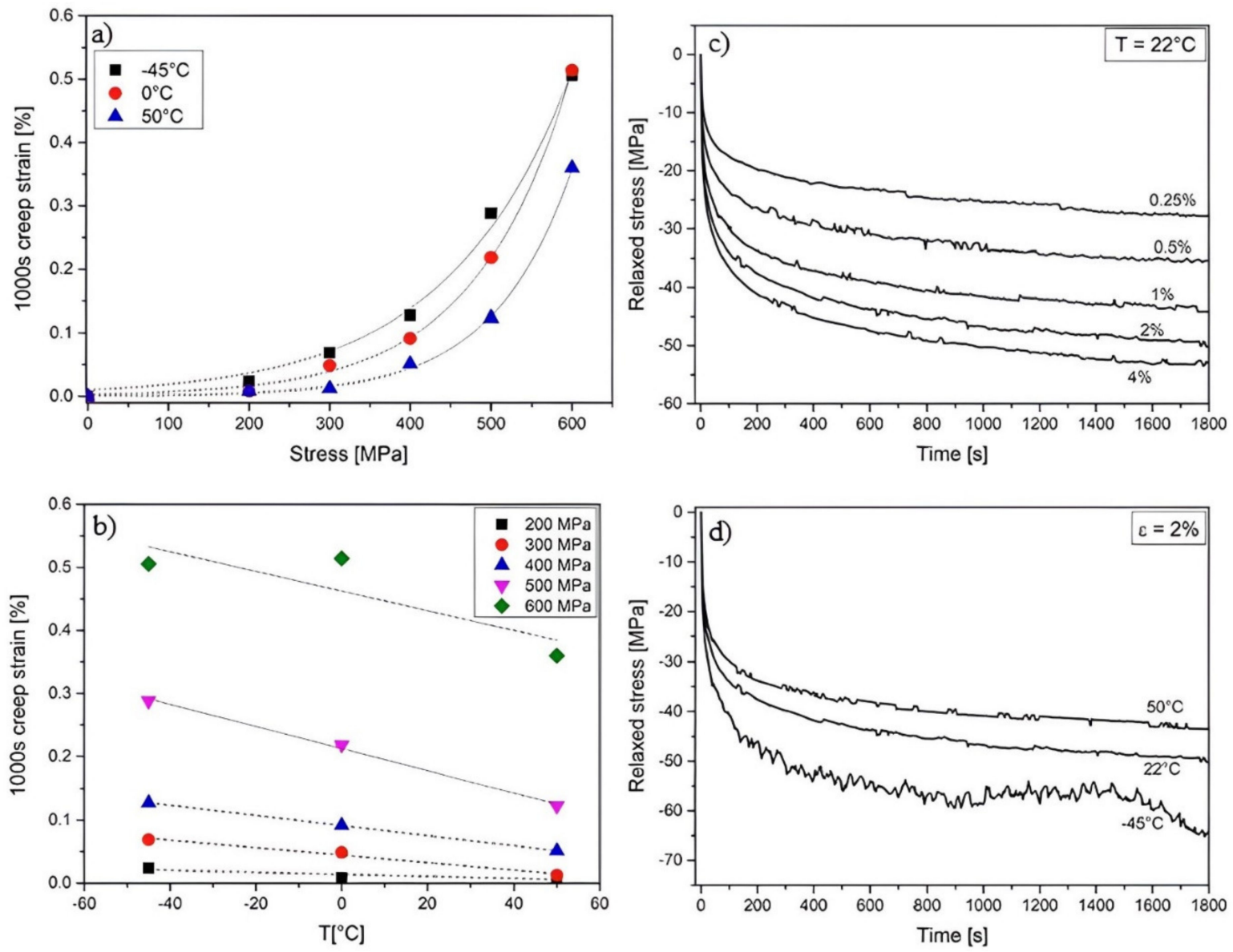

Figure 10. Creep and relaxation in SMA material: (a) creep strain after $1000 \mathrm{~s}$ as a function of constant stress; (b) creep strain after $1000 \mathrm{~s}$ as a function of temperature; (c) stress relaxation at room temperature for various constant strains; (d) stress relaxation at different temperatures for the strain of $2 \%$; Reprinted with permission from ref. [96]. Copyright 2016 Elsevier.

The prestressing level in CFRPs should be at least $25 \%$ and does not exceed $65 \%$ of the ultimate strength [98] (see Section 4.2). Prestressing equal to $50 \%$ of the CFRP tensile strength is suggested to be applied in the EAR technique due to technical and economic reasons $[72,98,99]$. However, $40 \%$ of the CFRP tensile strength is recommended for the NSMR technique [9]. In general, the recovery stress in memory steel is much smaller than the initial prestress in the CFRP reinforcement. Hence, in the case of a similar cross-section area of CFRP and SMA reinforcement, the prestressing force would be from two to four times higher for the CFRP prestressing.

\subsection{Influence of Durability}

Due to the non-metallic nature of CFRPs, these materials are fully corrosion-resistant. This is why environment exposure does not affect the decrease in the tensile CFRP strength $[100,101]$.

The corrosion resistance of memory steel has been investigated for various ironbased SMAs in [102-110]. Based on the previous studies that are summarized in Table 2, it can be concluded that the smaller the exchange current density ( $\left.\mathrm{i}_{\mathrm{corr}}\right)$, the higher the corrosion resistance of the material in the tested solution. Lee et al. [102] and Joo et al. [110] indicated that iron-based SMA has better corrosion resistance in comparison with the conventional steel of type S500 and S400, respectively. The vulnerability to corrosion in chloride environment due to high manganese $(\mathrm{Mn})$ content was identified in the study carried out by Rovere et al. [105]. Dias et al. [109] confirmed low corrosion resistance of the iron-based alloy regardless of different mechanical processing and heat treatment. Analysis 
of SEM images of the SMA surface after polarization tests at $\mathrm{pH} 8.4$ in solutions without chloride $\left(15 \mathrm{mM} \mathrm{NaHCO}_{3}+5 \mathrm{mM} \mathrm{Na}_{2} \mathrm{CO}_{3}\right)$ and with chloride $(15 \mathrm{mM} \mathrm{NaHCO} 3+5 \mathrm{mM}$ $\mathrm{Na}_{2} \mathrm{CO}_{3}+2.8 \mathrm{M} \mathrm{NaCl}$ ) was conducted by Lee et al. [102]. As it can be seen in Figure 11, the pitting corrosion is visible in the solution with chloride while no corrosion pits are on the surface of the sample in the solution without chloride. It can be concluded that the SMAs are very sensitive to the chloride contamination of concrete since the chloride ions cause their local de-passivation which leads to corrosion pittings. As the high manganese content decrease the corrosion resistance of alloy, high chromium $(\mathrm{Cr})$ and nickel $(\mathrm{Ni})$ content in the alloy causes higher corrosion resistance of SMA [107,108], see Figure 12. The corrosion behavior in $\mathrm{NaCl}$ environment can be also slightly improved by the addition of copper (Cu) [103] and Lanthanum (La) [104] or a small amount of cerium (Ce) [106]. Nevertheless, advanced corrosion protection should be taken into account and applied for structures in environments with high chloride concentrations. The externally applied reinforcement can be protected by the reactive coatings and the embedment in the cementitious matrix in the case of the NSM FeSMA [111].

Table 2. Electrochemical parameters of various types of FeSMAs and steel.

\begin{tabular}{|c|c|c|c|c|c|}
\hline Ref. & Material & Solution & $\begin{array}{l}\text { Chloride in } \\
\text { Solution }\end{array}$ & $\mathrm{pH}$ & $\begin{array}{c}\text { Exchange } \\
\text { Current Density } \\
\text { i }_{\text {corr }}\left[\mu \mathrm{A} / \mathrm{cm}^{2}\right]\end{array}$ \\
\hline [104] & $\begin{array}{l}\text { Fe-25Mn-6Si-5Cr } \\
\text { Fe-26Mn-6Si-5Cr-0.16La } \\
\text { Fe-25Mn-6Si-5Cr-0.30La } \\
\text { 18-8 stainless steel }\end{array}$ & $\begin{array}{l}3.5 \text { wt. } \% \mathrm{NaCl} \\
\text { aqueous solution }\end{array}$ & Yes & $\mathrm{N} / \mathrm{I}$ & $\begin{array}{c}671.82 \\
7.20 \\
58.31 \\
3.17\end{array}$ \\
\hline [102] & $\begin{array}{l}\text { Fe-17Mn-5Si-10Cr-4Ni-0.74V } \\
\text { S500 steel } \\
\text { Fe-17Mn-5Si-10Cr-4Ni-0.74V } \\
\text { S500 steel }\end{array}$ & $\begin{array}{l}15 \mathrm{mM} \mathrm{NaHCO}_{3}+5 \mathrm{mM} \\
\mathrm{Na}_{2} \mathrm{CO}_{3} 1.2 \mathrm{M} \mathrm{CH}_{3} \mathrm{COOH}+ \\
\text { 3.74 M CH} \mathrm{COONa}_{3} \mathrm{COO}\end{array}$ & No & $\begin{array}{l}8.4 \\
8.4 \\
4.5 \\
4.5\end{array}$ & $\begin{array}{c}0.67 \\
3.30 \\
0.57 \\
77.00\end{array}$ \\
\hline [106] & $\begin{array}{l}\text { Fe-14Mn-4Si-9Cr-4Ni } \\
\text { Fe-14Mn-4Si-9Cr-4Ni-0.18Ce } \\
\text { Fe-14Mn-4Si-9Cr-4Ni-0.42Ce } \\
\text { Fe-14Mn-4Si-9Cr-4Ni-0.96Ce }\end{array}$ & $\begin{array}{l}10 \mathrm{mM} \mathrm{Na}_{2} \mathrm{SO}_{4}+400 \mathrm{mM} \\
\mathrm{KOH}+1 \mathrm{mM} \mathrm{Ca}(\mathrm{OH})_{2}\end{array}$ & No & 13 & $\begin{array}{l}0.27 \\
0.28 \\
0.34 \\
0.33\end{array}$ \\
\hline [106] & $\begin{array}{l}\text { Fe-14Mn-4Si-9Cr-4Ni } \\
\text { Fe-14Mn-4Si-9Cr-4Ni-0.18Ce } \\
\text { Fe-14Mn-4Si-9Cr-4Ni-0.42Ce } \\
\text { Fe-14Mn-4Si-9Cr-4Ni-0.96Ce }\end{array}$ & $\begin{array}{l}10 \mathrm{mM} \mathrm{Na}_{2} \mathrm{SO}_{4}+400 \mathrm{mM} \\
\mathrm{KOH}+1 \mathrm{mM} \mathrm{Ca}(\mathrm{OH})_{2}+ \\
0.6 \mathrm{M} \mathrm{NaCl}\end{array}$ & Yes & 13 & $\begin{array}{l}0.36 \\
0.28 \\
1.99 \\
1.14\end{array}$ \\
\hline [110] & Fe-16Mn-5Si-4Ni-5Cr-0.3C-1Ti & $\begin{array}{l}3.5 \text { wt. } \% \mathrm{NaCl} \text { solution with } \\
\text { various pH values, adjusted } \\
\text { by } \mathrm{CaO}\end{array}$ & Yes & $\begin{array}{c}7 \\
9 \\
11 \\
13 \\
7 \\
9 \\
11 \\
13\end{array}$ & $\begin{array}{c}4.70 \\
3.20 \\
1.60 \\
0.38 \\
17.00 \\
4.30 \\
2.20 \\
0.77\end{array}$ \\
\hline
\end{tabular}

\subsection{Thermal Expansion Coefficients}

In the case of strengthening applications, proper thermal compatibility between the reinforced material and concrete is of great importance. A significant difference in the thermal expansion coefficients (CTE) imposes the additional stresses in the strengthened element that causes a decrease in the strengthening efficiency [112]. CTE of concrete is $10 \times 10^{-6} \mathrm{~K}^{-1}$ [113] and the steel reinforcement is in the range of $11-13 \times 10^{-6} \mathrm{~K}^{-1}$. The current study has demonstrated that the CTE of FeSMA is in the range of $14-16 \times 10^{-6} \mathrm{~K}^{-1}$ that is closed to other austenitic steel materials $[16,26,95]$. The study conducted by Fritsch et al. [114] confirmed a small change in the prestressing level of the FeSMA strip (which was anchored to steel substrate) during the high-cycle fatigue tests as a result of daily temperature changes. Insignificant 
changes in the FeSMA strengthened girder were observed by Hosseini et al. [15] as a result of the daytime and nighttime temperature variations. However, CTE of CFRPs (along fiber's direction) is close to 0 or even negative [34,115,116]. Hosseini et al. [95] demonstrated that the difference between the CTE of steel and the CFRP materials imposed the stress changes along with the CFRP plates due to the temperature changes during days and nights (the similar behavior for concrete with bonded CFRP can be expected). In another study by Hosseini et al. [117], the long-term measurement results showed that daily temperature changes can be the reason for the significant thermal-induced stress cycles in the non-prestressed bonded CFRP plate. Similar stress changes occurred in the prestressed unbonded CFRP plates. However, in this case, the stress was almost negligible compared to the existing CFRP prestressing level.
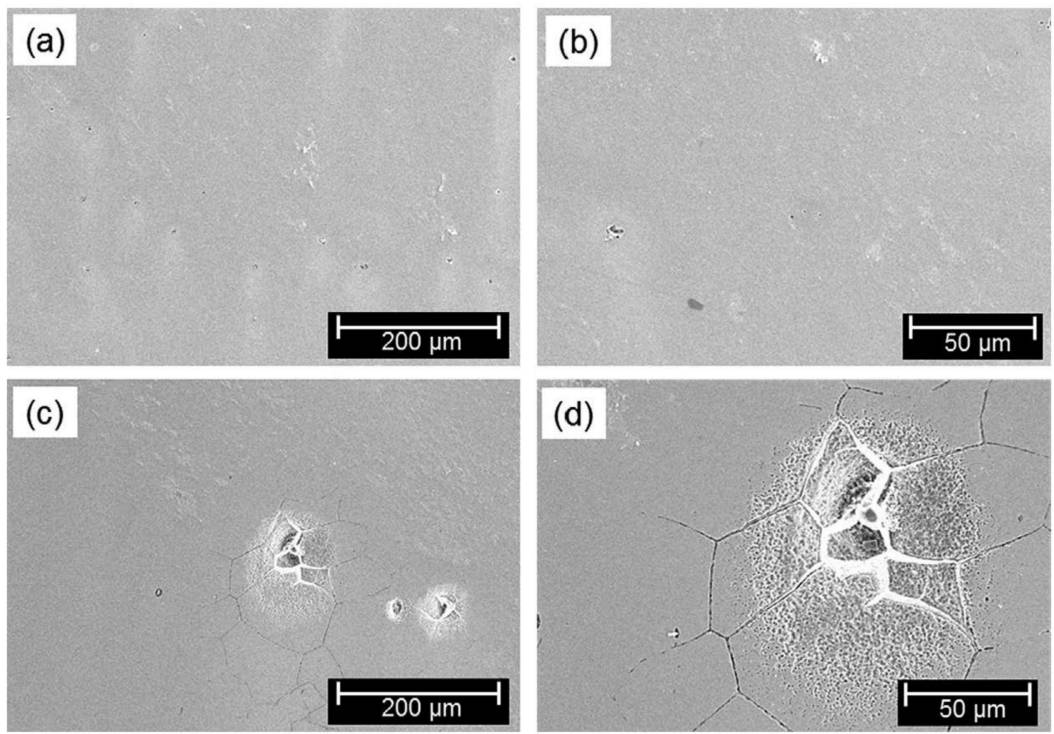

Figure 11. SEM images of corroded surfaces of SMA at pH 8.4: (a) without chloride, solution $15 \mathrm{mM}$ $\mathrm{NaHCO}_{3}+5 \mathrm{mM} \mathrm{Na} \mathrm{CO}_{3}$; (b) without chloride, the same solution, zoom in; (c) with chloride, solution $15 \mathrm{mM} \mathrm{NaHCO}_{3}+5 \mathrm{mM} \mathrm{Na}_{2} \mathrm{CO}_{3}+2.8 \mathrm{M} \mathrm{NaCl}$; (d) with chloride, the same solution, zoom in (Reprinted with permission from ref. [102]. Copyright 2015 John Wiley \& Sons-Book).

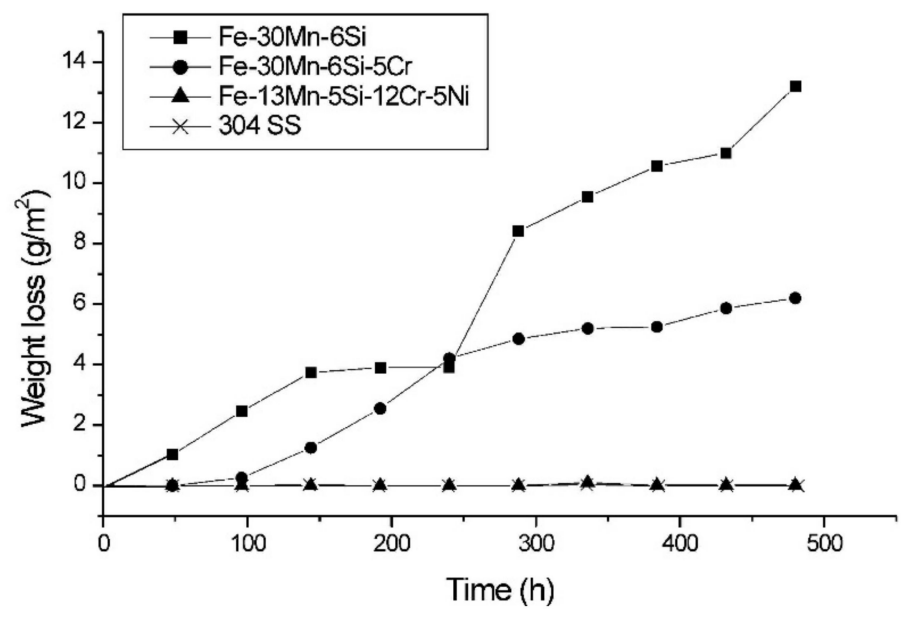

Figure 12. The weight loss in function of immersion time for different types of iron-based SMA and stainless-steel SUS 304 in a 3.5\% NaCl solution (Reprinted with permission from ref. [108]. Copyright 2002 Elsevier). 


\subsection{Behavior at Elevated Temperatures}

The complex study on the structural fire behavior of the prestressed FeSMA was carried out by Ghafoori et al. [118]. The series of transient total deformation tests were performed on the FeSMA strips to determine the creep-onset and failure temperatures of the alloy at various service stresses $(0,80$, and $240 \mathrm{MPa})$ and heating rates $(5,15$, and $\left.50{ }^{\circ} \mathrm{C} / \mathrm{min}\right)$. The results of experimental investigations indicated that creep-onset temperatures were greater than $500{ }^{\circ} \mathrm{C}$ for all aforementioned conditions. The corresponding failure temperatures were approximately $70{ }^{\circ} \mathrm{C}$ higher than $500{ }^{\circ} \mathrm{C}$. Moreover, the increase in the service stress caused a decrease in both the failure and creep-onset temperatures. The degradation of stiffness, yield, and ultimate strength of the memory steel subjected to elevated temperatures were similar to that of structural steel reinforcement investigated in [119]. The Young modulus and the ultimate strength of the FeSMA decreased by $20 \%$ with the temperature increase from ambient temperature to $400{ }^{\circ} \mathrm{C}$ (see Figure 13). The prestress losses increased with the temperature increase and the prestressing stress reduced to zero at about $320^{\circ} \mathrm{C}$. The prestress losses can be delayed by applying protective fire insulation materials.
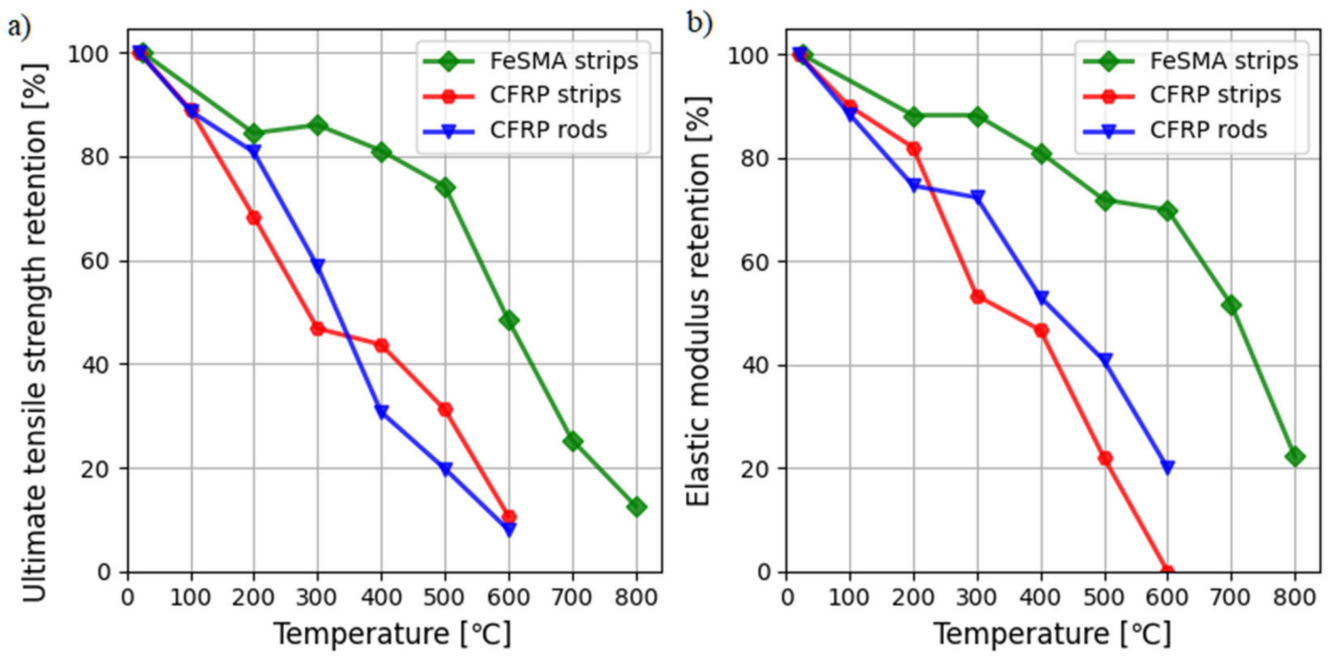

Figure 13. Parameters of FeSMA and CFRP materials at elevated temperatures based on the data given in $[118,120]$ : (a) ultimate tensile strength retention; (b) elastic modulus retention.

The fire behavior of CFRP materials applied for strengthening concrete structures was investigated by Bisby et al. [121] and Firmo et al. [122]. These tests indicated that CFRPs subjected to elevated temperature suffer degradation in strength and stiffness $[120,123,124]$. The reduction in the ultimate strength and Young's modulus is about $50 \%$ at $400{ }^{\circ} \mathrm{C}$ (see Figure 13). The most dangerous was FRP matrix degradation when exposed to the temperature of $300-400{ }^{\circ} \mathrm{C}$, which caused releasing of heating and toxic gases [122,125]. Hence, it is necessary to provide proper fire protection not only due to CFRP degradation but due to smoke toxicity. However, conducted research [126,127] demonstrated the efficiency of thermal insulation to protect CFRP strengthened concrete members.

\section{Literature Review}

A limited number of research studies containing a comparison of flexural strengthening using CFRP and FeSMA materials have been conducted so far. The experiments and computational analysis based on literature $[17,19,61,128-131]$ are summarized in Table 3. Other research studies dedicated to flexural strengthening using iron-based memory steel are summarized in Table 4. Finally, Table 5 presents selected research on flexural strengthening with prestressed CFRP materials. 
Table 3. Experimental and numerical tests of RC members strengthened with FeSMA and CFRP materials.

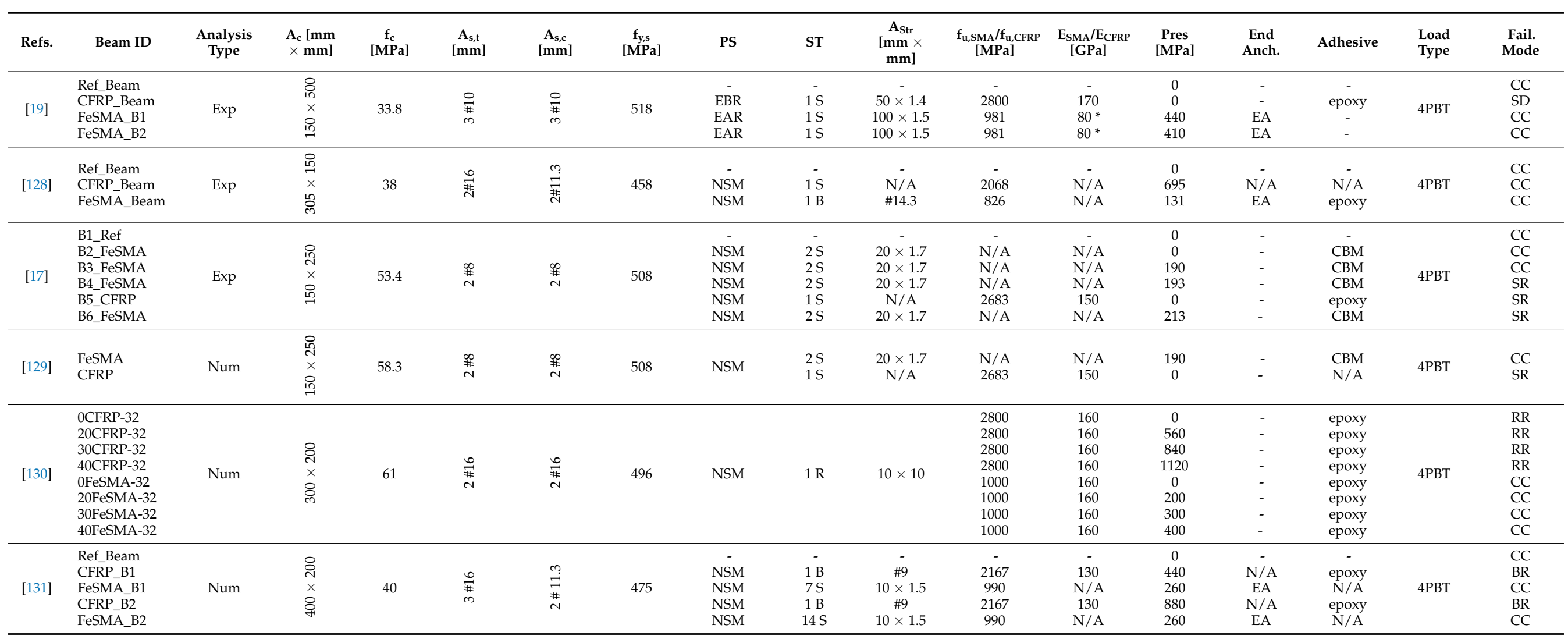

Analysis type: Exp, experimental tests and Num, numerical analysis; $A_{c}$, dimensions of concrete cross section [height $\times$ width]; $\mathrm{f}_{\mathrm{c}}$, concrete compressive strength; $\mathrm{A}_{\mathrm{s}, \mathrm{t}}$, tensile steel reinforcement [number of bars \#diameter]; $A_{s, c}$, compressivee steel reinforcement [number of bars \#diameter]; $\mathrm{f}_{\mathrm{y}, \mathrm{s}}$, steel yielding strength; PS, prestressing system: EBR, externally bonded reinforcement, EAR, externally applied reinforcement, NSM, near-surface mounted reinforcement and shot is reinforcement embedded in a shotcrete layer; $\mathrm{ST}$, strengthening type: $\mathrm{S}$ acronym of strip, $\mathrm{B}$, acronym of bar, R, acronym of rod; $\mathrm{A}_{\mathrm{Str}}$, dimensions of SMA/CFRP cross section [width $\times$ depth or \#diameter]; $\mathrm{f}_{\mathrm{u}, \mathrm{SMA}} / \mathrm{f}_{\mathrm{CFRP}}, \mathrm{ultimate}$ strength of SMA/CFRP; $\mathrm{E}_{\mathrm{SMA}} / \mathrm{E}_{\mathrm{CFRP}}$, young modulus of SMA/CFRP: * means that young modulus after activation was given; End anch., end anchorage (acronym EA means that reinforcement was anchored of its end); Adhesive: CBM, cement based mortar, epoxy is epoxy adhesive, shot is a shotcrete layer; Load type: 4PBT, four point bending test; FAT, a fatigue test; CAN, test with force on the slab cantilever; Fail. mode, failure mode: CC, concrete crushing after steel yielding; SD, strip debonding; ICD, interfacial debonding; CCS, concrete cover separation; AF, anchorage failure; SR, BR, and RR, strip, bar or rod rupture, respectively; N/A, data not available. 
Table 4. Experimental and numerical tests of RC members strengthened with FeSMA materials.

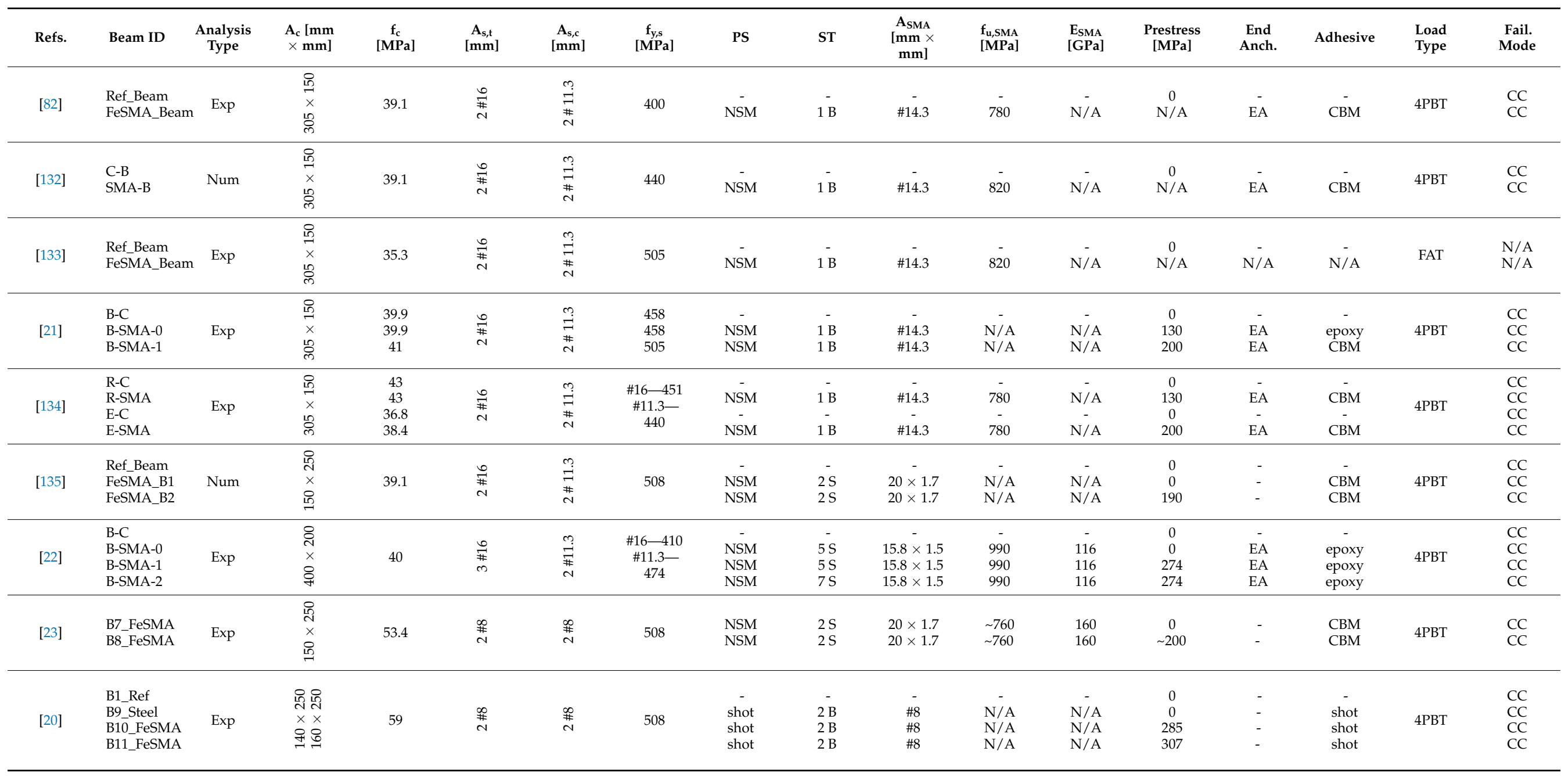


Table 4. Cont.

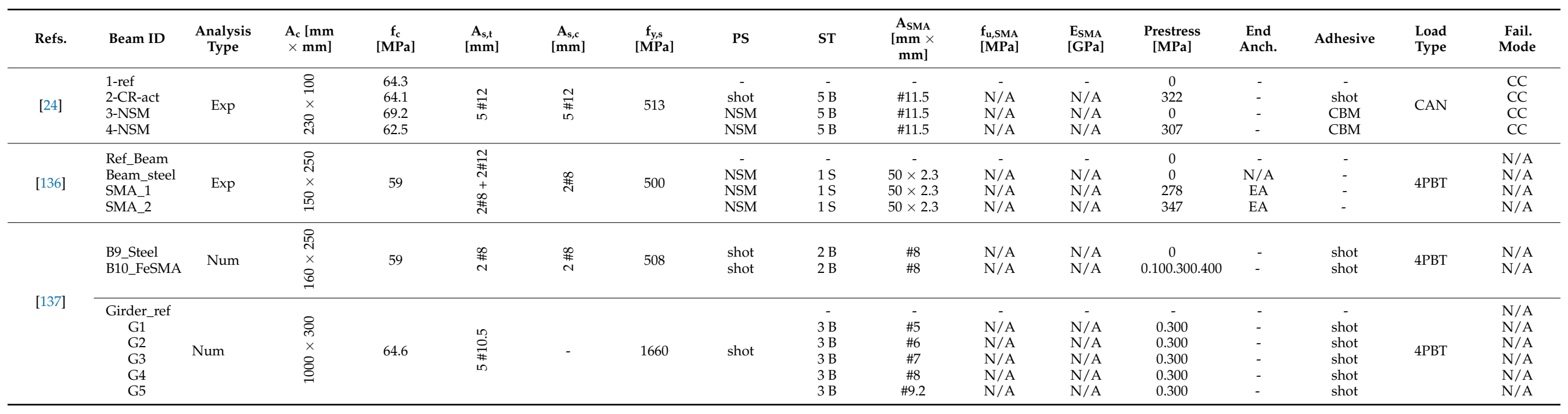

Table 5. Experimental and numerical tests of RC members strengthened with CFRP materials.

\begin{tabular}{|c|c|c|c|c|c|c|c|c|c|c|c|c|c|c|c|c|c|}
\hline Refs. & Beam ID & $\begin{array}{c}\text { Analysis } \\
\text { type }\end{array}$ & $\begin{array}{r}\mathrm{A}_{\mathrm{c}}[\mathrm{mm} \\
\times \mathbf{m m}]\end{array}$ & $\begin{array}{c}\mathbf{f}_{\mathrm{c}} \\
{[\mathrm{MPa}]}\end{array}$ & $\begin{array}{c}\mathbf{A}_{\mathrm{s}, \mathrm{t}} \\
{[\mathrm{mm}]}\end{array}$ & $\begin{array}{c}\mathbf{A}_{\mathrm{s}, \mathrm{c}} \\
{[\mathrm{mm}]}\end{array}$ & $\begin{array}{c}\mathbf{f}_{\mathrm{ys}} \\
{[\mathrm{MPa}]}\end{array}$ & PS & ST & $\begin{array}{c}A_{\text {CFRP }} \\
{[\mathrm{mm} \times} \\
\mathrm{mm}]\end{array}$ & $\begin{array}{l}\mathrm{f}_{\mathrm{u}, \mathrm{CFRP}} \\
\text { [MPa] }\end{array}$ & $\begin{array}{l}E_{\text {CFRP }} \\
\text { [Gpa] }\end{array}$ & $\begin{array}{l}\text { Prestress } \\
\text { [MPa] }\end{array}$ & $\begin{array}{l}\text { End } \\
\text { Anch. }\end{array}$ & Adhesive & $\begin{array}{l}\text { Load } \\
\text { Type }\end{array}$ & $\begin{array}{l}\text { Fail. } \\
\text { Mode }\end{array}$ \\
\hline$[58]$ & $\begin{array}{l}\text { Contro } \\
10 \% \text { Prestress. } \\
40 \% \text { Prestress. } \\
60 \% \text { Prestress. }\end{array}$ & Exp & 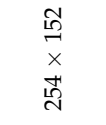 & 45 & 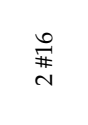 & 2 \# 11.3 & 440 & $\begin{array}{l}- \\
\text { NSM } \\
\text { NSM } \\
\text { NSM }\end{array}$ & $\begin{array}{l}- \\
1 \mathrm{~B} \\
1 \mathrm{~B} \\
1 \mathrm{~B}\end{array}$ & $\begin{array}{l}- \\
- \\
\# 9.5 \\
\# 9.5 \\
\# 9.5\end{array}$ & $\begin{array}{c}- \\
1970 \\
1970 \\
1970\end{array}$ & $\begin{array}{l}- \\
136 \\
136 \\
136\end{array}$ & $\begin{array}{c}0 \\
0 \\
788 \\
1182\end{array}$ & $\begin{array}{l}- \\
- \\
- \\
-\end{array}$ & $\begin{array}{l}- \\
\text { epoxy } \\
\text { epoxy } \\
\text { epoxy }\end{array}$ & $4 \mathrm{PBT}$ & $\begin{array}{l}\text { CC } \\
\text { CC } \\
\text { BR } \\
\text { BR }\end{array}$ \\
\hline [59] & $\begin{array}{l}\text { B00 } \\
\text { B2-0\% } \\
\text { B2-20\% } \\
\text { B2-40\% } \\
\text { B2-60\% } \\
\end{array}$ & Exp & $\begin{array}{l}8 \\
\stackrel{+}{1} \\
\times \\
8 \\
8\end{array}$ & 40 & $\stackrel{D}{\#}$ & 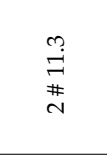 & $\begin{array}{c}\# 16-475 \\
\# 11.3- \\
500\end{array}$ & $\begin{array}{l}- \\
\text { NSM } \\
\text { NSM } \\
\text { NSM } \\
\text { NSM }\end{array}$ & $\begin{array}{l}- \\
1 \text { B } \\
1 \text { B } \\
1 \text { B } \\
1 \text { B }\end{array}$ & $\begin{array}{l}- \\
\# 9 \\
\# 9 \\
\# 9 \\
\# 9 \\
\end{array}$ & $\begin{array}{c}- \\
2068 \\
2068 \\
2068 \\
2068 \\
\end{array}$ & $\begin{array}{c}- \\
124 \\
124 \\
124 \\
124 \\
\end{array}$ & $\begin{array}{c}0 \\
0 \\
414 \\
827 \\
1241 \\
\end{array}$ & $\begin{array}{l}- \\
\text { EA } \\
\text { EA } \\
\text { EA } \\
\text { EA }\end{array}$ & $\begin{array}{l}- \\
\text { epoxy } \\
\text { epoxy } \\
\text { epoxy } \\
\text { epoxy }\end{array}$ & $4 \mathrm{PBT}$ & $\begin{array}{l}\text { N/A } \\
\text { BR } \\
\text { BR } \\
\text { BR } \\
\text { BR }\end{array}$ \\
\hline [138] & $\begin{array}{l}\text { SREF } \\
\text { S2L-0 } \\
\text { S2L-20 } \\
\text { S2L-40 }\end{array}$ & Exp & $\begin{array}{l}8 \\
8 \\
\times \\
\stackrel{7}{-1}\end{array}$ & 15 & 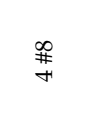 & 异 & $\begin{array}{l}\# 8-556 \\
\# 6-528\end{array}$ & $\begin{array}{l}\text { NSM } \\
\text { NSM } \\
\text { NSM }\end{array}$ & $\begin{array}{l}2 S \\
2 S \\
2 S\end{array}$ & $\begin{array}{l}20 \times 1.4 \\
20 \times 1.4 \\
20 \times 1.4\end{array}$ & $\begin{array}{l}2770 \\
2770 \\
2770\end{array}$ & $\begin{array}{l}176 \\
176 \\
176\end{array}$ & $\begin{array}{c}0 \\
0 \\
554 \\
1108\end{array}$ & $\begin{array}{l}- \\
- \\
- \\
-\end{array}$ & $\begin{array}{l}\text { e- } \\
\text { epoxy } \\
\text { epoxy } \\
\text { epoxy }\end{array}$ & 4 РВТ & $\begin{array}{l}\text { CC } \\
\text { SR } \\
\text { SR } \\
\text { SR }\end{array}$ \\
\hline
\end{tabular}


Table 5. Cont.

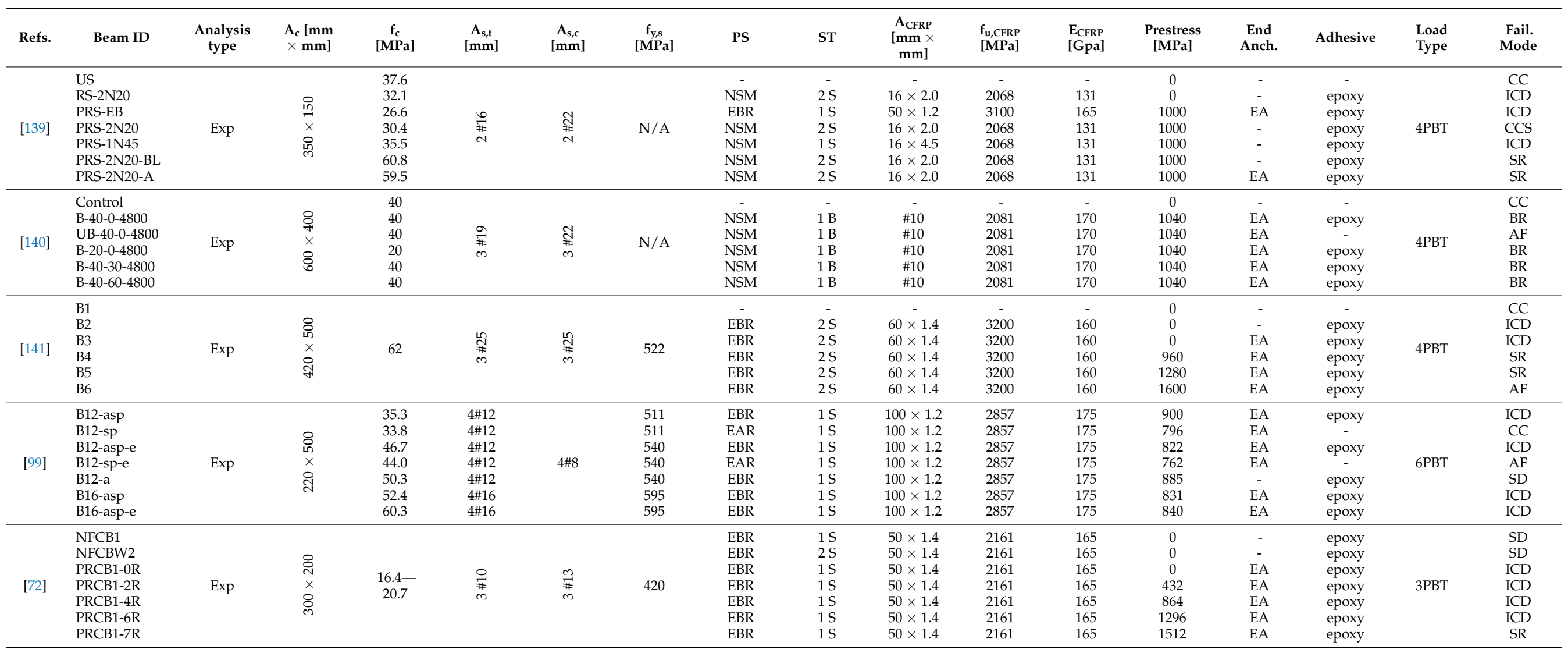


Analysis of previous studies (mentioned in the above tables) revealed that different failure modes are exhibited for RC beams strengthened with FeSMA and CFRP materials. The majority of FeSMA beams failed due to concrete crushing after yielding steel (as unstrengthened reference beams) which is connected with their low longitudinal steel reinforcement ratio. In two prestressed beams [17], one of the FeSMA strips ruptured shortly before concrete was crushed. It should be highlighted that no anchorage failure was observed. The failure mode of beams strengthened with CFRP materials depends on factors such as the prestressing technique, prestressing level, anchorages, and adhesives. The most common failure mode was connected with debonding or rupture of the bar, strip, or rod. In some cases, anchorage failure or sliding of strip end from anchorage took place.

Selected results from the previous studies are presented in Table 6. Prestressing increased the cracking load and deflection. Strengthening with FeSMA materials allowed to keep the ductile behavior similar to unstrengthened RC beams with higher value of cracking, yielding and ultimate loads while the behavior of beams strengthened with CFRP was much more brittle with a significant reduction in ultimate deflection. However, the ultimate beam capacity was greater for beams with CFRP compared to that with memory steel.

Table 6. Selected results from the previous studies.

\begin{tabular}{|c|c|c|c|c|c|c|c|c|c|}
\hline Refs. & Beam ID & $\begin{array}{l}\text { Prestress } \\
\text { [MPa] }\end{array}$ & $\begin{array}{c}\mathbf{P}_{\mathrm{cr}} \\
{[\mathbf{k N}]}\end{array}$ & $\begin{array}{c}\Delta_{\mathrm{cr}} \\
{[\mathrm{mm}]}\end{array}$ & $\begin{array}{c}\mathbf{P}_{\mathbf{y}} \\
{[\mathbf{k N}]}\end{array}$ & $\begin{array}{c}\Delta_{y} \\
{[\mathrm{~mm}]}\end{array}$ & $\begin{array}{c}\mathbf{P}_{\mathbf{u}} \\
{[\mathbf{k N}]}\end{array}$ & $\begin{array}{c}\Delta_{\mathrm{u}} \\
{[\mathrm{mm}]}\end{array}$ & $\begin{array}{c}\mathrm{I}_{\mathrm{D}}=\underset{\mathrm{H}}{\Delta_{\mathrm{u}}} / \Delta_{\mathrm{y}} \\
\end{array}$ \\
\hline \multirow{4}{*}{ [19] } & Ref_Beam & 0 & 1.0 & 0.8 & 5.6 & 40.0 & 7.9 & 145.0 & 3.63 \\
\hline & CFRP__Beam & 0 & 2.0 & 1.2 & 11.3 & 49.0 & 14.9 & 75.0 & 1.53 \\
\hline & FeSMA_B1 & 440 & 3.4 & 3.2 & 11.7 & 39.0 & 17.1 & 105.0 & 2.69 \\
\hline & FeSMA_B2 & 410 & 5.6 & 3.2 & 12.8 & 42.0 & 15.4 & 135.0 & 3.21 \\
\hline \multirow{3}{*}[128]{} & Ref_Beam & 0 & 19.0 & $\mathrm{~N} / \mathrm{A}$ & 104.0 & 5.3 & 124.0 & 18.0 & 3.40 \\
\hline & CFRP_Beam & 695 & 43.0 & $\mathrm{~N} / \mathrm{A}$ & 141.0 & 5.3 & 178.1 & 16.5 & 3.11 \\
\hline & FeSMA_Beam & 131 & 40.0 & $\mathrm{~N} / \mathrm{A}$ & 126.9 & 5.8 & 165.4 & 27.5 & 4.74 \\
\hline \multirow{6}{*}{ [17] } & B1_Ref & 0 & 2.0 & $\mathrm{~N} / \mathrm{A}$ & $\mathrm{N} / \mathrm{A}$ & $\mathrm{N} / \mathrm{A}$ & 9.8 & 48.7 & $\mathrm{~N} / \mathrm{A}$ \\
\hline & B2_FeSMA & 0 & 2.5 & $\mathrm{~N} / \mathrm{A}$ & $\mathrm{N} / \mathrm{A}$ & $\mathrm{N} / \mathrm{A}$ & 16.8 & 70.6 & $\mathrm{~N} / \mathrm{A}$ \\
\hline & B3_FeSMA & 190 & 4.5 & $\mathrm{~N} / \mathrm{A}$ & $\mathrm{N} / \mathrm{A}$ & $\mathrm{N} / \mathrm{A}$ & 16.9 & 56.9 & $\mathrm{~N} / \mathrm{A}$ \\
\hline & B4_FeSMA & 193 & 4.7 & $\mathrm{~N} / \mathrm{A}$ & $\mathrm{N} / \mathrm{A}$ & $\mathrm{N} / \mathrm{A}$ & 16.8 & 51.1 & $\mathrm{~N} / \mathrm{A}$ \\
\hline & B5̄_CFRP & 0 & 2.4 & $\mathrm{~N} / \mathrm{A}$ & $\mathrm{N} / \mathrm{A}$ & $\mathrm{N} / \mathrm{A}$ & 22.9 & 55.9 & $\mathrm{~N} / \mathrm{A}$ \\
\hline & B6_FeSMA & 213 & 4.2 & $\mathrm{~N} / \mathrm{A}$ & $\mathrm{N} / \mathrm{A}$ & $\mathrm{N} / \mathrm{A}$ & 16.4 & 52.0 & $\mathrm{~N} / \mathrm{A}$ \\
\hline \multirow{2}{*}{ [129] } & FeSMA & 190 & $\mathrm{~N} / \mathrm{A}$ & $\mathrm{N} / \mathrm{A}$ & $\sim 13.0$ & $\mathrm{~N} / \mathrm{A}$ & $\sim 16.6$ & $\sim 83.0$ & $\mathrm{~N} / \mathrm{A}$ \\
\hline & CFRP & 0 & $\mathrm{~N} / \mathrm{A}$ & $\mathrm{N} / \mathrm{A}$ & $\sim 13.0$ & $\mathrm{~N} / \mathrm{A}$ & $\sim 22.5$ & $\sim 60.0$ & $\mathrm{~N} / \mathrm{A}$ \\
\hline \multirow{8}{*}[130]{} & 0CFRP-32 & 0 & 15.2 & 2.0 & 93.9 & 20.5 & 127.6 & 45.8 & 2.24 \\
\hline & 20CFRP-32 & 560 & 27.5 & 2.1 & 110.7 & 20.0 & 130.4 & 32.0 & 1.60 \\
\hline & 30CFRP-32 & 840 & 28.6 & 2.0 & 120.5 & 19.6 & 138.3 & 31.0 & 1.58 \\
\hline & 40CFRP-32 & 1120 & 29.3 & 2.0 & 128.5 & 20.2 & 131.5 & 26.8 & 1.32 \\
\hline & 0FeSMA-32 & 0 & 13.8 & 2.5 & 83.2 & 29.3 & 105.7 & 72.2 & 2.75 \\
\hline & 20FeSMA-32 & 200 & 22.1 & 2.6 & 94.3 & 27.4 & 108.2 & 60.5 & 2.48 \\
\hline & 30FeSMA-32 & 300 & 23.6 & 2.5 & 101.7 & 25.9 & 111.3 & 58.4 & 2.45 \\
\hline & 40FeSMA-32 & 400 & 24.5 & 2.4 & 109.5 & 24.2 & 114.7 & 54.6 & 2.38 \\
\hline \multirow{5}{*}[131]{} & Ref_Beam & 0 & 32.0 & 3.3 & 82.4 & 22.5 & 90.7 & 157.8 & 7.01 \\
\hline & CFRP_B1 & 440 & 52.6 & 4.5 & 119.0 & 26.6 & 160.9 & 91.9 & 3.45 \\
\hline & FeSMA_B1 & 260 & 53.6 & 4.2 & 120.0 & 24.3 & 145.0 & 163.5 & 6.72 \\
\hline & CFRP_B2 & 880 & 65.5 & 4.3 & 136.0 & 24.3 & 162.8 & 53.0 & 2.18 \\
\hline & FeSMA_B2 & 260 & 65.0 & 4.0 & 153.0 & 25.8 & 188.9 & 139.6 & 5.40 \\
\hline
\end{tabular}

$\mathrm{P}_{\mathrm{cr}}, \mathrm{P}_{\mathrm{y}}$, and $\mathrm{P}_{\mathrm{u}}$ are cracking, yielding and ultimate loads, respectively; $\Delta_{\mathrm{cr}}, \Delta_{\mathrm{y}}$, and $\Delta_{\mathrm{u}}$ are deflection at cracking yielding and ultimate, respectively; $\mathrm{I}_{\mathrm{D}}$ is a ductility index, calculated as deflection at ultimate load divided by deflection at yielding load; N/A means that the data are not available.

To highlight the better ductility of the FeSMA strengthened beams compared to that strengthened with the CFRP reinforcement, the ductility index was introduced in Table 6. It was calculated as the ratio of mid-span deflections at ultimate and steel yielding states. The ductility index was much higher for the beams with FeSMAs. The yielding nature of the memory steel caused the higher deflections of RC beams before the concrete crushing.

Michels et al. [19] compared reinforced concrete beams with various types of strengthening: without strengthening, passive strengthening with bonded CFRP strips without 
end-anchorage and active strengthening with FeSMA strips. The FeSMA strips were fixed to the concrete with the direct fastening method that fully resisted the anchorage zones from debonding. The structural behavior of beams strengthened with FeSMA was more ductile than the beam with CFRP strips that failed due to CFRP debonding. The CFRP and concrete compressive strains were equal to $6.9 \%$ and $1.0 \%$, respectively, which confirmed only partial utilization of CFRP strips and concrete. However, the beams prestressed with FeSMA strips failed due to the concrete crushing with a maximal concrete strain equal to $2.5 \%$. For unbonded external prestressing tendon, more concentrated beam rotation occurred within the maximal bending moment zone with a slightly lower ultimate concrete compressive strain value $[19,142]$. Although all of the beams had similar crack spacing, the smaller length of crack distribution occurred in the beams strengthened with FeSMAs.

Five RC beams strengthened with NSM reinforcements and one reference beam without strengthening were analyzed by Shahverdi et al. in [17]. The beams had different types of strengthening: one beam reinforced with two non-activated FeSMA strips, three beams with two activated FeSMA strips and one beam strengthened by only one non-prestressed CFRP strip (to gain a similar strengthening effect). The FeSMA strips were only glued with cement-based mortar in grooves (without end anchorages) and their bond behavior was good. The prestressed beam exhibited much better performance in serviceability state (e.g., higher cracking load and smaller mid-span deflections (up to a load of $\sim 12 \mathrm{kN}$ )). However, prestressing does not increase the ultimate load in comparison to the non-prestressed beam with FeSMA which is similar behavior to the conventional prestressing. It was confirmed by Shahverdi et al. in [129] who carried out the nonlinear simulation based on the previous study and effects of various parameters (e.g., prestressing level, FeSMA or steel reinforcement ratio, compressive strength of concrete) on the structural behavior of NSM FeSMA beam were analyzed. The increase in ultimate load and deflection was observed when the concrete compressive strength increased but the cracking and yielding deflections and loads did not change significantly. The prestressing with NSM FeSMA strips was more efficient for beams with a low steel reinforcement ratio.

A study by Raad and Parvin [130] presents finite element analysis of the flexural strengthening of RC beams using NSM CFRP, GFRP and SMA rods. Moreover, several beams were strengthened with the hybrid (both CFRP and GFRP) or coupled CFRP-FeSMA rods. The effects of different prestressing levels $(0 \%, 20 \%, 30 \%$, and $40 \%$ of the ultimate strength) were investigated. The behavior of both CFRP and FeSMA strengthened beams was similar for all prestressing levels before cracking. Higher prestressing level caused slightly higher cracking load and higher yielding load for both materials. The steel yielding and the ultimate loads of the beams strengthened with FeSMAs were slightly lower (by $11-16 \%$ and $13-20 \%$, respectively) in comparison with the CFRP strengthened beams, but they had a significantly higher increase in the ultimate deflection (by about 50\%).

A numerical comparison of RC beams strengthened with the NSM techniques was conducted in [131]. One reference beam, two beams reinforced using prestressed CFRP rod and two beams with activated FeSMA strips were analyzed. Two different prestressing forces (28 and $56 \mathrm{kN}$ ) for each prestressing method were used, but different ways were used to gain these effects. The number of strips was twice higher in the case of the FeSMA beam, while the CFRP strips were prestressed with the higher initial strain (FeSMA_Beam2 and CFRP_Beam2, respectively; Table 3). These parameters led to the higher axial stiffness of the FeSMA beam and resulted in the higher ultimate load. However, all of the beams with the additional reinforcement exhibited a comparable behavior at cracking and steel yielding load. Failure of the CFRP beams was brittle, while the reference and FeSMA beams exhibited a ductile failure mode with much higher ultimate deflection.

\section{Practical Implementations}

The first flexural strengthening strips of real structure with prestressed FeSMA happened in 2017 in Villigen, Switzerland [19,79]. The additional reinforcement was needed since the static system was changed by the removal of load bearing wall. To ensure minimal 
loss of room height the combination of three strengthening methods was used. The $24 \mathrm{~cm}$ thick slab was strengthened by a steel girder installed between two supporting walls and 14 prestressed FeSMA strips applied in the perpendicular directions. Moreover, the lack of overlap of lower steel reinforcement perpendicular to the removed wall was covered by applications of 12 CFRP strips. The scheme of strengthening and finished strengthening project are presented in Figure 14. The FeSMA strips were anchored with nails using a direct fastening system and activated by resistive heating. This heating method caused the activation process is carried out simultaneously through the whole FeSMA strip. It should be mentioned that the location of the internal steel reinforcement of the slab near the end anchorage should be verified to prevent direct contact and possible short circuit.

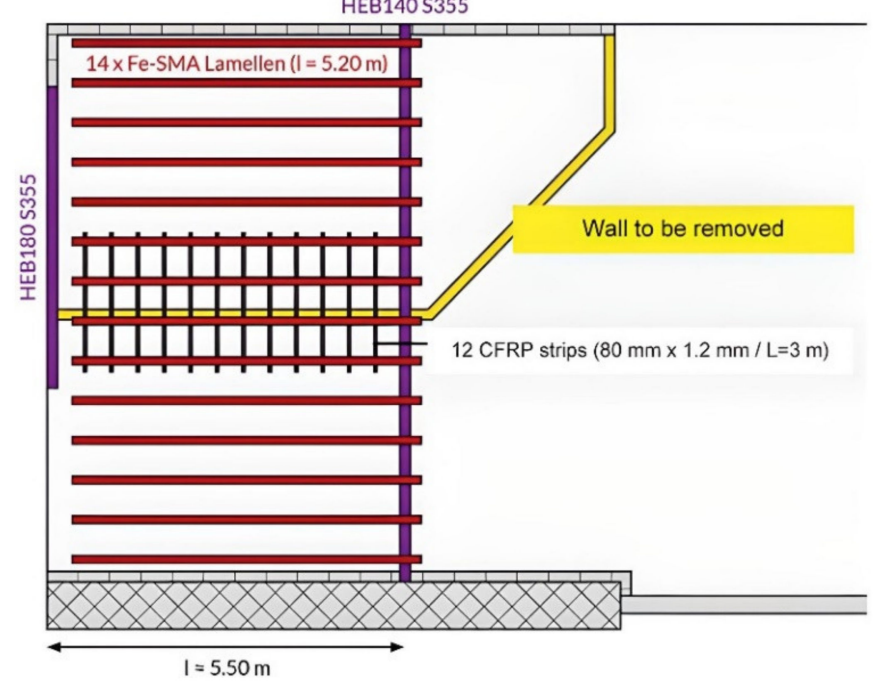

(a)

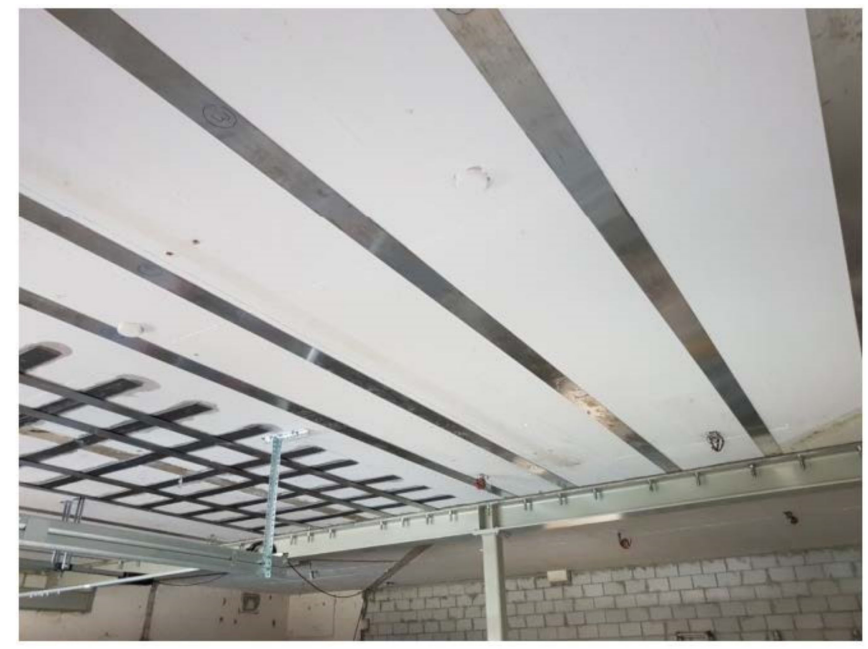

(b)

Figure 14. The strengthening of the slab in carpentry in Switzerland: (a) scheme of strengthening (republished from [19]); (b) view after strengthening (republished from [79]).

Another possibility of activation FeSMA strips is infrared heating, which was used during strengthening a slab in Arrau, Switzerland [79]. A new column was placed and hence the tensile steel reinforcement of the slab in the negative moment area was insufficient. The FeSMA strips were inserted into grooves to provide an even concrete surface after retrofitting. After activation, the strips were covered with a bonding coat and then the grooves were grouting with a cementitious mortar. The activation process using infrared heating devices does not require a high-power supply as resistive heating (see Figure 15). However, since the infrared heating device is usually shorter than the SMA strip, the activation process takes more time and is carried out sequentially which causes a wide temperature variation in the strip. Strieder et al. [136] indicated that sequentially heating may slightly influence the prestressing level. Further research that compares different heating methods is highly recommended.

Modernization of reinforced concrete bridge in Komańcza, Poland was required due to its deterioration and narrow roadway $[11,44]$. The deck had to be widened from $8.9 \mathrm{~m}$ to $11.2 \mathrm{~m}$. To increase the load capacity of the bridge, the bridge girders were strengthened using prestressed CFRP strips in 2015. The $60 \times 1.4 \mathrm{~mm}$ strips were applied to the bottom surfaces of beams in mid span and the top surface of the deck over the bridge supports. The bridge was not close to traffic during modernization, hence the strengthening took place in three stages. Firstly, the road surface was milled, the waterproofing was removed, and the strips were installed to the top surface on one half of the deck. Then the bottom surface of the girders was prepared by grinding and the strips were applied to the girders in the main span. Finally, the traffic was redirected and the strips were bonded to the top surface of the second half of the bridge deck. The prestressing force of each strip was estimated 
as $75 \mathrm{kN}$. The strip application and view of the bridge after strengthening are presented in Figure 16. The effect of strengthening was verified by comparison strains (of concrete, steel and CFRP strips) and deflections in the main span before (between stages 1 and 2) and after strengthening of the girders. The test load was applied by two 38 tons trucks. The results revealed that the deflections before and after strengthening were almost the same. It was expected due to the small cross section area of the strips in comparison with beam cross section and the small test load that induced relatively low internal forces. This additional load induced the average stresses of $16.5 \mathrm{MPa}$ in the CFRP strips. However, the $23 \%$ average reduction of stresses in the tensile steel reinforcement was observed after strengthening that confirmed the effectiveness of the strengthening.

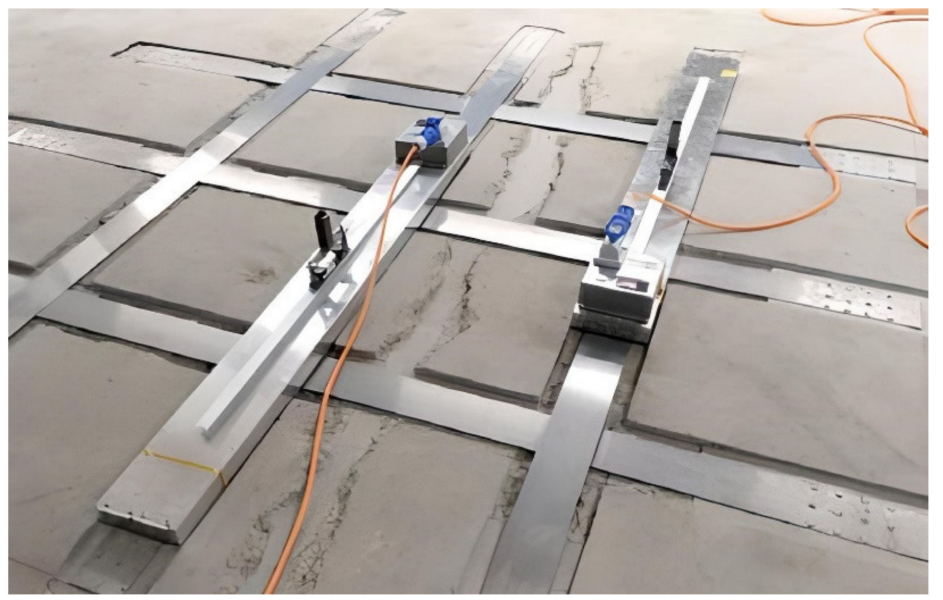

Figure 15. Activation process using infrared heating devices (republished from [79]).

a)

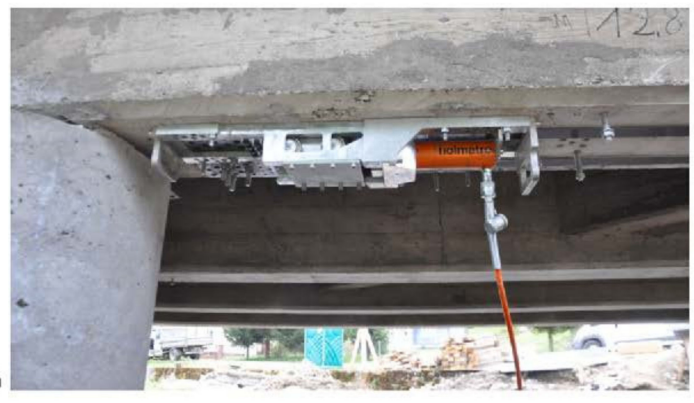

b)

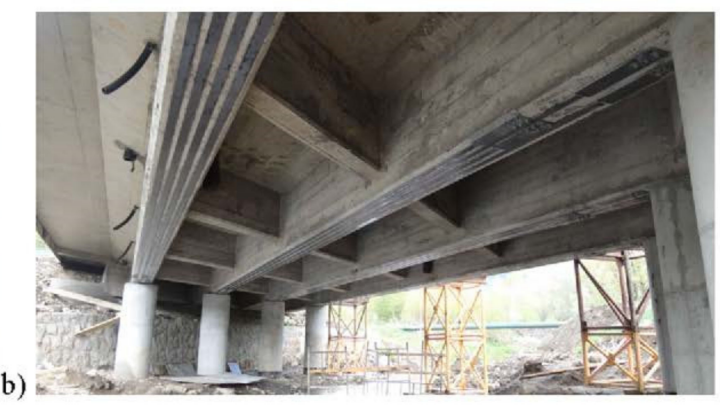

Figure 16. Strengthening of the bridge in Komańcza, republished from [11]: (a) prestressing the CFRP strip; (b) view of the bridge after strengthening.

The NSM technique was used to strengthen a four-span bridge in Gyeonggi-do, South Korea [143]. The bridge was supported by RC girders. Each girder was strengthened by two CFRP bars. Prestress level of the bar was approximately equal to $100 \mathrm{kN}$. The prestressing procedure is presented in Figure 17. First of all, the cover thickness and location of steel reinforcement had to be identified. Then, two grooves in each girder were cut using a portable saw-cut machine which was rolled on a trolley along the girder length. In the next stage, steel anchorages were mounted in the cavities between the steel reinforcement of the girders to avoid structural damage. Then, the installation of CFRP bars by threading through the anchor blocks took place. Next, the prestressing force was applied by a hydraulic jack to reach the planned value. After adjusting the fastening nut to hold the force, the jacking device was removed. Finally, epoxy was used to fill all of the grooves and cavities. Before and after strengthening, static (with truck weighing $324 \mathrm{kN}$ placed at the mid span) and dynamic (with the same truck moving $50 \mathrm{~km} / \mathrm{h}$ ) tests were carried out. The results revealed that the maximum displacement of the girders after strengthening decreased from 0.48 to $0.35 \mathrm{~mm}$ and from 0.51 to $0.40 \mathrm{~mm}$ during static and dynamic tests, respectively. 
The reduction in strains of steel bars was observed in both tests. The strains decreased by 32 and $26 \%$ for static and dynamic loading, respectively. Obtained results confirmed the effectiveness of strengthening to improve the serviceability limit state.

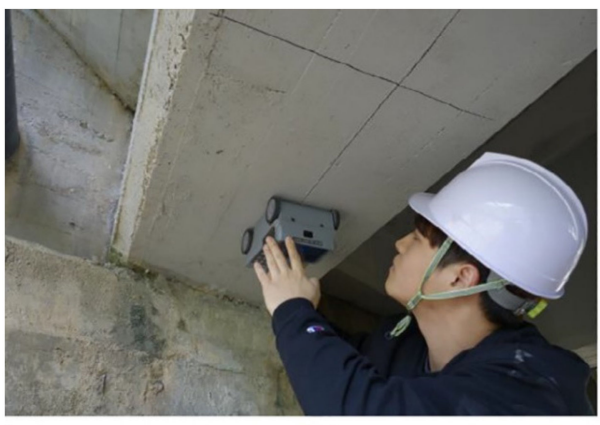

(a)

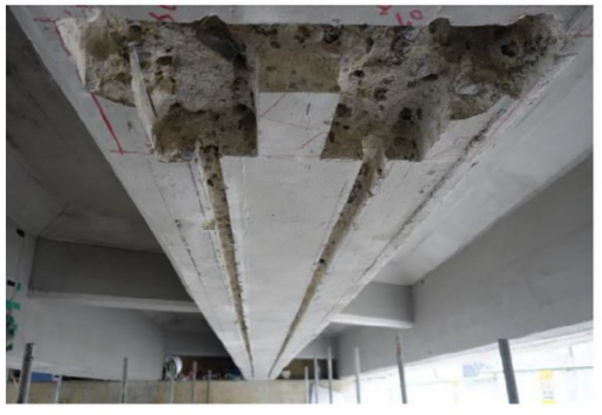

(c)

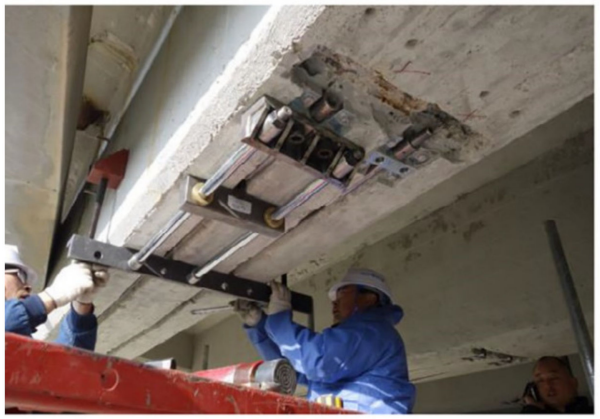

(e)

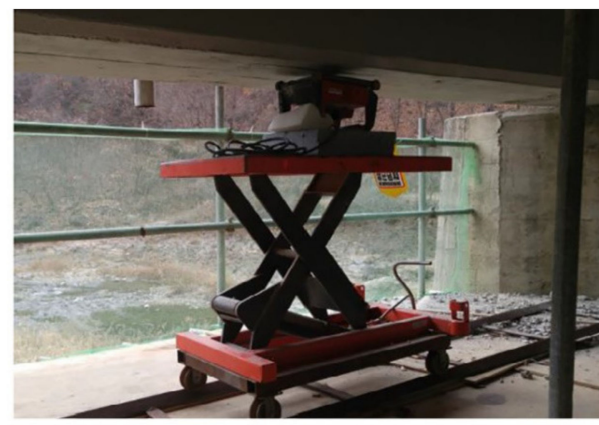

(b)

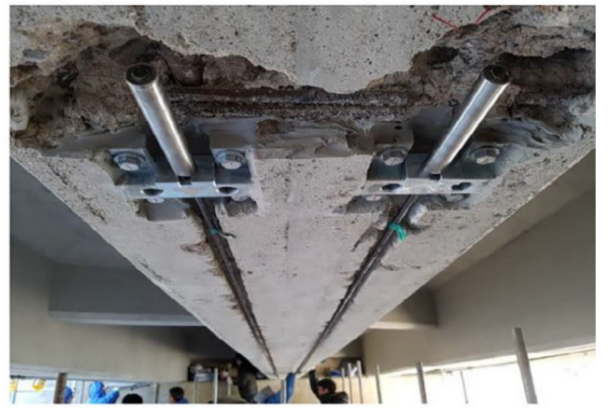

(d)

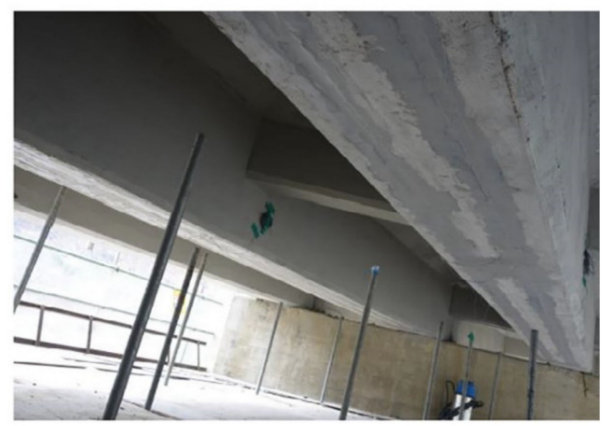

(f)

Figure 17. Process of bridge strengthening: (a) inspection to identify the thickness of the covering and the location of the steel reinforcement; (b) cutting the grooves; (c) view of the grooves; (d) installation of the anchorage and the CFRP bars.; (e) applying prestressing; (f) filling the grooves with an epoxy. Reprinted with permission from ref. [143]. Copyright 2018 Elsevier.

\section{Conclusions}

In this paper, current state-of-the-art developments in terms of prestressed concrete structures using SMA or CFRP reinforcement is presented. Both materials are compared in terms of the material level considering tensile behavior, durability aspects and effects of elevated temperature. Moreover, the prestressing methods and anchorage systems are briefly described. Additional item concerns previous studies considering both experiments and numerical analysis and summary of CFRP and SMA strengthened RC members. The following conclusion can be drawn:

1. The strengthening of concrete structures with prestressed CFRP and SMA materials is significantly efficient in serviceability states, including higher cracking load and reduced deflections. The effectiveness of flexural strengthening was confirmed both in laboratory tests and practical implementations. 
2. Prestressing using SMAs can be an interesting alternative to prestressing with CFRP materials, especially due to the future price reduction of SMAs.

3. SMA materials can be used as prestressed near surface mounted or externally applied reinforcement. In both cases, they are much easier to apply anchors and activate SMA compared to CFRP materials, which usually require specialized equipment. The FeSMAs are activated by heating to the temperature, which is usually in the range of $130-200{ }^{\circ} \mathrm{C}$.

4. The activation process can be performed using different methods: resistive heating, infrared heating or heating using a gas burner. The prestressing level may be affected by the activation method, however further research on this topic is recommended.

5. The prestressing level of SMAs depends on the type of the alloy, activation temperature and the initial prestraining level. In the presented state of the art, the shape recovery stress was in the range of 130-450 MPa, which resulted in 2-4 times lower prestressing forces than by using CFRP reinforcement. Hence, the flexural capacity of the beams strengthened with CFRP bars and strips is higher than SMAs.

6. The most common failure mode for beams strengthened with CFRP reinforcement was CFRP rupture or CFRP delamination, while the beams strengthened with FeSMAs exhibited usually a failure due to concrete crushing after the steel yielding. A proper design of strengthening using CFRP reinforcement is needed to utilize their high tensile strength and to prevent the brittle failure mode.

7. The behavior of SMA is very ductile that allows the RC members to obtain much higher deflections. The ductility index for all beams strengthened with SMA was much higher than for CFRP strengthened beams.

8. Two important factors should be considered during the design of strengthening using prestressed memory steel. In first the elasticity modulus depends on the actual state of the alloy since the initial value is twice higher than the value after activation. The latter is appropriate for design purposes. Secondly, the compressive strains in concrete should be limited to $2-2.5 \%$ as the SMA reinforcement behaves similarly as the external prestressed unbonded tendon.

9. The thermal compatibility with concrete is much better in the case of SMAs, since they have a slightly higher coefficient of thermal expansion than concrete. As the coefficient of thermal expansion of CFRP is close to 0 or even negative the stress changes occur along with the bonded CFRP reinforcements due to the temperature changes.

10. The memory steel exhibits much better performance compared to CFRP when is subjected to elevated temperatures. Additionally, heating and toxic gases are released due to thermal decompositions of the FRP matrix when exposed to a temperature of $300-400{ }^{\circ} \mathrm{C}$. Hence, it is necessary to provide proper fire protection not only due to the strength degradation but also due to the smoke toxicity.

11. The prestress losses in the RC members strengthened with prestressed CFRP materials occurs in the first $100 \mathrm{~h}$ and a further decrease in prestressing is negligible, while the memory steel is affected by long-term creep and stress relaxation. The current studies estimate that the prestress losses due to relaxation are about $15 \%$. However, they might be retrieved by second or multiple activations.

12. The CFRPs are fully corrosion resistant due to their non-metallic structure, while SMAs are susceptible to corrosion and that should be taken into account in long-term durability. Memory steel is especially sensitive to chloride ions, which intensifies the pitting corrosion. Hence, additional corrosion protection should be applied for structures in aggressive environments.

13. On-site tests confirmed the practicality of flexural strengthening using prestressed CFRPs for RC bridge structures under dynamic load conditions.

14. Strengthening with FeSMA materials can be combined with other strengthening techniques (e.g., non-prestressed CFRP strips) to ensure maximum gains in serviceability and ultimate limit states. 
Future research is necessary to develop the current knowledge of strengthening RC structures with prestressed SMA materials. The following recommendations should be taken into future research:

1. The prestress losses and long-term behavior of SMAs used for prestressing of RC structures.

2. The prestressing losses due to the slippage at anchorages should be analyzed.

3. Developing more precise methods of determining prestressing level in memory steel after its application to RC structure.

4. Effects of different heating methods on the prestressing level in SMA materials.

5. The possibility of multiple activations should be developed.

6. The behavior of SMA in chemical environments considering effects on recovery stress or bonding behavior should be investigated in more detail.

7. Feasibility of SMA materials for flexural strengthening of RC structures under dynamic load conditions.

8. Effectiveness of corrosion protection applied to SMA materials.

9. Design guidelines for prestressing with SMA should be organized.

10. Comparison of prestressing techniques using SMA and unbonded CFRP reinforcement with end-anchorages.

Author Contributions: Conceptualization, J.R. and R.K.; methodology, J.R.; state of the art, J.R. and R.K.; data analysis, J.R. and R.K.; writing-original draft preparation, J.R.; writing-review and editing, R.K. All authors have read and agreed to the published version of the manuscript.

Funding: This research received no external funding.

Institutional Review Board Statement: Not applicable.

Informed Consent Statement: Not applicable.

Data Availability Statement: The data presented in this study are available on request from the corresponding author.

Acknowledgments: This paper has been completed while the first author was the Doctoral Candidate in the Interdisciplinary Doctoral School at the Lodz University of Technology, Poland.

Conflicts of Interest: The authors declare no conflict of interest.

\section{References}

1. Al-Mahaidi, R.; Kalfat, R. Methods of structural rehabilitation and strengthening. In Rehabilitation of Concrete Structures with Fiber-Reinforced Polymer; Elsevier: Amsterdam, The Netherlands, 2018; pp. 7-13. [CrossRef]

2. Hollaway, L.C. A review of the present and future utilisation of FRP composites in the civil infrastructure with reference to their important in-service properties. Constr. Build. Mater. 2010, 24, 2419-2445. [CrossRef]

3. Mugahed Amran, Y.H.; Alyousef, R.; Rashid, R.S.M.; Alabduljabbar, H.; Hung, C.C. Properties and applications of FRP in strengthening RC structures: A review. Structures 2018, 16, 208-238. [CrossRef]

4. Naser, M.Z.; Hawileh, R.A.; Abdalla, J.A. Fiber-reinforced polymer composites in strengthening reinforced concrete structures: A critical review. Eng. Struct. 2019, 198, 109542. [CrossRef]

5. Siddika, A.; Mamun, M.A.; Al, M.; Ferdous, W.; Alyousef, R. Performances, challenges and opportunities in strengthening reinforced concrete structures by using FRPs-A state-of-the-art review. Eng. Fail. Anal. 2020, 111, 104480. [CrossRef]

6. Siwowski, T.; Radomski, W. The Polish experience in bridge strengthening with CFRP composites. In Proceedings of the SMAR 2015: Third Conference on Smart Monitoring, Assessment and Rehabilitation of Civil Structures, Antalya, Turkey, 7-9 September 2015.

7. Kotynia, R.; Staśkiewicz, M.; Michels, J.; Czaderski, C.; Motavalli, M. Pioneering strengthening of bridge girders with pretensioned CFRP laminates in Poland. In Proceedings of the SMAR 2015 Third Conference on Smart Monitoring, Assessment and Rehabilitation of Civil Structures, Antalya, Turkey, 7-9 September 2015.

8. Grelle, S.V.; Sneed, L.H. Review of anchorage systems for externally bonded FRP laminates. Int. J. Concr. Struct. Mater. 2013, 7, 17-33. [CrossRef]

9. Aslam, M.; Shafigh, P.; Jumaat, M.Z.; Shah, S.N.R. Strengthening of RC beams using prestressed fiber reinforced polymers-A review. Constr. Build. Mater. 2015, 82, 235-256. [CrossRef]

10. Siwowski, T.; Żółtowski, P. Strengthening bridges with prestressed CFRP strips. Sel. Sci. Pap. J. Civ. Eng. 2012, 7, 79-86. [CrossRef]

11. Siwowski, T.; Piątek, B.; Siwowska, P.; Wiater, A. Development and implementation of CFRP post-tensioning system for bridge strengthening. Eng. Struct. 2020, 207, 110266. [CrossRef] 
12. Mohd Jani, J.; Leary, M.; Subic, A.; Gibson, M.A. A review of shape memory alloy research, applications and opportunities. Mater. Des. 2014, 56, 1078-1113. [CrossRef]

13. Janke, L.; Czaderski, C.; Motavalli, M.; Ruth, J. Applications of shape memory alloys in civil engineering structures-Overview, limits and new ideas. Mater. Struct. Constr. 2005, 38, 578-592. [CrossRef]

14. Dong, Z.; Klotz, U.E.; Leinenbach, C.; Bergamini, A.; Czaderski, C.; Motavalli, M. A Novel Fe-Mn-Si shape memory alloy with improved shape recovery properties by VC precipitation. Adv. Eng. Mater. 2009, 11, 40-44. [CrossRef]

15. Hosseini, A.; Michels, J.; Izadi, M.; Ghafoori, E. A comparative study between Fe-SMA and CFRP reinforcements for prestressed strengthening of metallic structures. Constr. Build. Mater. 2019, 226, 976-992. [CrossRef]

16. Czaderski, C.; Shahverdi, M.; Brönnimann, R.; Leinenbach, C.; Motavalli, M. Feasibility of iron-based shape memory alloy strips for prestressed strengthening of concrete structures. Constr. Build. Mater. 2014, 56, 94-105. [CrossRef]

17. Shahverdi, M.; Czaderski, C.; Motavalli, M. Iron-based shape memory alloys for prestressed near-surface mounted strengthening of reinforced concrete beams. Constr. Build. Mater. 2016, 112, 28-38. [CrossRef]

18. Shahverdi, M.; Michels, J.; Czaderski, C.; Motavalli, M. Iron-based shape memory alloy strips for strengthening RC members: Material behavior and characterization. Constr. Build. Mater. 2018, 173, 586-599. [CrossRef]

19. Michels, J.; Shahverdi, M.; Czaderski, C. Flexural strengthening of structural concrete with iron-based shape memory alloy strips. Struct. Concr. 2018, 19, 876-891. [CrossRef]

20. Shahverdi, M.; Czaderski, C.; Annen, P.; Motavalli, M. Strengthening of RC beams by iron-based shape memory alloy bars embedded in a shotcrete layer. Eng. Struct. 2016, 117, 263-273. [CrossRef]

21. Rojob, H.; El-Hacha, R. Self-prestressing using iron-based shape memory alloy for flexural strengthening of reinforced concrete beams. ACI Mater. J. 2017, 114, 523-532. [CrossRef]

22. El-Hacha, R.; Rojob, H. Flexural strengthening of large-scale reinforced concrete beams using near-surface-mounted selfprestressed iron-based shape-memory alloy strips. PCI J. 2018, 63, 55-65. [CrossRef]

23. Shahverdi, M.; Czaderski, C. Long-term behavior of reinforced concrete beams strengthened by iron-based shape memory alloy strips. In Proceedings of the SMAR 2019: Fifth International Conference on Smart Monitoring, Assessment and Rehabilitation of Civil Structures, Potsdam, Germany, 27-29 August 2019.

24. Schranz, B.; Michels, J.; Czaderski, C.; Motavalli, M.; Vogel, T.; Shahverdi, M. Strengthening and prestressing of bridge decks with ribbed iron-based shape memory alloy bars. Eng. Struct. 2021, 241, 112467. [CrossRef]

25. Humbeeck, J. Shape memory alloys: A material and a technology. Adv. Eng. Mater. 2001, 3, 837-850. [CrossRef]

26. Cladera, A.; Weber, B.; Leinenbach, C.; Czaderski, C.; Shahverdi, M.; Motavalli, M. Iron-based shape memory alloys for civil engineering structures: An overview. Constr. Build. Mater. 2014, 63, 281-293. [CrossRef]

27. Lagoudas, D.; Kumar, P.K. Introduction to Shape Memory Alloys. In Shape Memory Alloys: Modeling and Engineering Applications; Lagoudas, D.C., Ed.; Springer: New York, NY, USA, 2008; pp. 1-51. ISBN 978-0-387-47684-1.

28. Van Humbeeck, J.; Liu, Y. The High Damping Capacity of Shape Memory Alloys. In Shape Memory Implants; Yahia, L., Ed.; Springer: Berlin/Heidelberg, Germany, 2000; pp. 46-60. ISBN 978-3-642-59768-8.

29. Saadat, S.; Salichs, J.; Noori, M.; Hou, Z.; Davoodi, H.; Bar-On, I.; Suzuki, Y.; Masuda, A. An overview of vibration and seismic application of NiTi shape memory alloy. Smart Mater. Struct. 2002, 11, 218. [CrossRef]

30. Pan, Q.; Cho, C. Damping Property of Shape Memory Alloys. In Proceedings of the 17th International Metallurgical and Materials Conference METAL 2008, Hradec nad Moravici, Czech Republic, 13-15 May 2008.

31. Czaderski, C.; Weber, B.; Shahverdi, M.; Motavalli, M.; Leinenbach, C.; Lee, W.; Brönnimann, R.; Michels, J. Iron-based shape memory alloys (Fe-SMA) - A new material for prestressing concrete structures. In Proceedings of the SMAR 2015: Third Conference on Smart Monitoring, Assessment and Rehabilitation of Structures, Antalya, Turkey, 7-9 September 2015.

32. Michels, J.; Shahverdi, M.; Czaderski, C.; Schranz, B.; Motavalli, M. Iron based shape memory alloy strips, part 2: Flexural strengthening of RC beams. In Proceedings of the SMAR 2017: Fourth International Conference on Smart Monitoring, Assessment and Rehabilitation of Civil Structures, Zurich, Switzerland, 13-15 September 2017.

33. Czaderski, C.; Shahverdi, M.; Ghafoori, E.; Motavalli, M.; Leinenbach, C.; Arabi-Hashemi, A.; Michels, J.; Scherer, J. The development of memory steel at Empa. In Proceedings of the SMAR 2015: Fifth International Conference on Smart Monitoring, Assessment and Rehabilitation of Civil Structures, Potsdam, Germany, 27-29 August 2019.

34. Kotynia, R. FRP Composites for Flexural Strengthening of Concrete Structures Theory, Testing, Design; Lodz University of Technology Press: Lodz, Poland, 2019; ISBN 978-83-7283-996-1. [CrossRef]

35. Matthys, S.; Triantafillou, T.; Balazs, G.; Barros, J.; Bilotta, A.; Bournas, D.; Ceroni, F.; Czaderski, C.; D'Antino, T.; Kolyvas, C.; et al. Fib Bulletin 90. Externally Applied FRP Reinforcement for Concrete Structures; The International Federation for Structural Concrete: Lausanne, Switzerland, 2019; ISBN 978-2-88394-132-8. [CrossRef]

36. Wu, H.-C.; Eamon, C.D. Strengthening of Concrete Structures Using Fiber Reinforced Polymers (FRP): Design, Construction and Practical Applications; Wu, H.-C., Eamon, C.D., Eds.; Woodhead Publishing: Sawston, UK, 2017; ISBN 978-0-08-100636-8.

37. Meier, U. Carbon Fiber-Reinforced Polymers: Modern Materials in Bridge Engineering. Struct. Eng. Int. 1992, 2, 7-12. [CrossRef]

38. Meier, U.; Deuring, M.; Meier, H.; Schwegler, G. 7. Strengthening of structures with advanced composites. In Alternative Materials for the Reinforcement and Prestressing of Concrete; Clarke, J.L., Ed.; Blackie Academic and Professional: Glasgow, UK, 1993.

39. Siwowski, T.; Radomski, W. First Polish application of CFRP laminates to strengthening of RC bridge. Inżynieria Bud. 1998, R. 54, 382-388.

40. Siwowski, T. CFRP materials for Strengthening concrete Bridges. Mosty 2012, 4, 24-29. 
41. Furtak, K. Strengthening of road viaduct by composite carbon fibres strips. Inżynieria $i$ Bud. 1998, R. 54, $435-437$.

42. Furtak, K. Technical assessment of RC bridge after 12 years from structural strengthening with carbon fibre reinforced polymer laminates. Arch. Civ. Eng. Inst. 2014, 18, 17-26.

43. Piatek, B. New Strengthening Technology of Strengthening Concrete Structures with Prestressed CFRP Laminates. Ph.D. Thesis, Technical University of Rzeszów, Rzeszów, Poland, 2017.

44. Siwowski, T.; Piatek, B. Investigation of strengthening effectiveness of reinforced concrete bridge with prestressed CFRP strips. Roads Bridg. Drog. Most. 2017, 15, 301-314. [CrossRef]

45. Siwowski, T.; Piątek, B. Research on the new CFRP prestressing system for strengthening of RS structures. Archit. Civ. Eng. Environ. 2017, 10, 81-87. [CrossRef]

46. Siwowski, T.; Michałowski, J.; Błażewicz, S. New prestressing system for strengthening RC structures with CFRP laminates. Inżynieria Bud. 2010, 66, 152-156.

47. Kotynia, R.; Lasek, K.; Staskiewicz, M. Flexural behavior of preloaded RC slabs strengthened with prestressed CFRP laminates. J. Compos. Constr. 2014, 18, A4013004. [CrossRef]

48. Teng, J.G.; fei Chen, J.; Smith, S.T.; Lam, L. FRP: Strengthened RC Structures; John Wiley \& Sons Ltd.: Chichester, UK, 2002; ISBN 0-471-48706-6.

49. Smith, S.T.; Teng, J.G. FRP-strengthened RC beams. I: Review of debonding strength models. Eng. Struct. 2002, 24, 385-395. [CrossRef]

50. Leinenbach, C.; Kramer, H.; Bernhard, C.; Eifler, D. Thermo-mechanical properties of an Fe-Mn-Si-Cr-Ni-VC shape memory alloy with low transformation temperature. Adv. Eng. Mater. 2012, 14, 62-67. [CrossRef]

51. Schlaich, M.; Zwingmann, B.; Goller, R. Zugelemente aus CFK und ihre Verankerungen. Bautechnik 2012, 89, 841-850. [CrossRef]

52. Michels, J.; Barros, J.; Costa, I.; Sena-Cruz, J.; Czaderski, C.; Giacomin, G.; Kotynia, R.; Lees, J.; Pellegrino, C.; Zile, E. Prestressed FRP systems. In Design Procedures for the Use of Composites in Strengthening of Reinforced Concrete Structures. State-of-the-Art Report of the RILEM Technical Committee 234-DUC; Pellegrino, C., Sena-Cruz, J., Eds.; Springer: Dordrecht, The Netherlands; Heidelberg, Germany; New York, NY, USA; London, UK, 2016; Volume 19, pp. 263-301. ISBN 978-94-017-7336-2.

53. El-Hacha, R.; Rojob, H. FRP prestressing systems for flexural strengthening of structural Elements-A review. In Proceedings of the 8th International Conference on Fibre-Reinforced Polymer (FRP) Composites in Civil Engineering CICE 2016, Hong Kong, China, 14-16 December 2016.

54. Berset, T.; Schwegler, G.; Trausch, L. Verstärkung einer Autobahnbrücke mit vorgespannten CFK-Lamellen. Tec21 2002, 128 , 27. [CrossRef]

55. El-Hacha, R.; Wight, G.; Green, M. Innovative system for prestressing fiber-reinforced polymer sheets. ACI Struct. J. $2003,100,305-313$.

56. Nordin, H. Fibre Reinforced Polymers in Civil Engineering: Flexural Strengthening of Concrete Structures with Prestressed near Surface Mounted CFRP Rods. Master's Thesis, Luleå University of Technology, Luleå, Sweden, 2003.

57. Rezazadeh, M.; Barros, J. Transfer zone of prestressed CFRP reinforcement applied according to NSM technique for strengthening of RC structures. Compos. Part B Eng. 2015, 79, 581-594. [CrossRef]

58. Badawi, M.; Soudki, K. Flexural strengthening of RC beams with prestressed NSM CFRP rods-Experimental and analytical investigation. Constr. Build. Mater. 2009, 23, 3292-3300. [CrossRef]

59. El-Hacha, R.; Gaafar, M. Flexural strengthening of reinforced concrete beams using prestressed, near-surface-mounted CFRP bars. PCI J. 2011, 56, 134-151. [CrossRef]

60. Kotynia, R.; Baky, H.A.; Neale, K.W. Bond behaviour of near-surface mounted strips in RC beams-Experimental investigation and numerical simulations. Materials 2021, 14, 4362. [CrossRef] [PubMed]

61. El-Hacha, R.; Hadiseraji, M. Strengthening RC beams with prestressed near-surface mounted CFRP strip. In Proceedings of the 7th International Conference on FRP Composites in Civil Engineering CICE 2014, Vancouver, BC, Canada, 20-22 August 2014.

62. S\&P FRP Systems. Available online: https:/ / www.sp-reinforcement.eu/en-EU/systems/sp-frp-systems / (accessed on 29 December 2021).

63. Andrä, H.-P.; König, G.; Maier, M. First Applications of CFRP tendons in Germany. IABSE Symp. Rep. 2002, 86, 103-110. [CrossRef]

64. Meier, U.; Stöcklin, I. A novel carbon fiber reinforced polymer (CFRP) system for post- strengthening. In Proceedings of the International Conference of Concrete Repair, Rehabilitation and Retrofitting (ICCRRR), Cape Town, South Africa, 21-23 November 2005.

65. Michels, J.; Sena-Cruz, J.; Czaderski, C.; Motavalli, M. Structural strengthening with prestressed CFRP strips with gradient anchorage. J. Compos. Constr. 2013, 17, 651-661. [CrossRef]

66. Czaderski, C. Strengthening of Reinforced Concrete Members by Prestressed, Externally Bonded Reinforcement with Gradient Anchorage. Ph.D. Thesis, ETH Zurich, Zurich, Switzerland, 2012.

67. Haghani, R.; Al-Emrani, M. A new method and device for application of bonded pre-stressed FRP laminates. In Proceedings of the Second International Conference on Advances in Civil and Structural Engineering, CSE 2, Kuala Lumpur, Malaysia, 20-21 December 2014.

68. El-Hacha, R.; Aly, M.Y.E. Anchorage System to Prestress FRP Laminates for Flexural Strengthening of Steel-Concrete Composite Girders. J. Compos. Constr. 2012, 17, 324-335. [CrossRef]

69. Kim, Y.J.; Wight, R.G.; Green, M.F. Flexural strengthening of RC beams with prestressed CFRP sheets: Development of nonmetallic anchor systems. J. Compos. Constr. 2008, 12, 35-43. [CrossRef] 
70. Wight, R.G.; Green, M.F.; Erki, M.-A. Prestressed FRP sheets for poststrengthening reinforced concrete beams. J. Compos. Constr. 2001, 5, 214-220. [CrossRef]

71. El-Hacha, R.; Green, M.F.; Wight, R.G. Flexural behaviour of concrete beams strengthened with prestressed carbon fibre reinforced polymer sheets subjected to sustained loading and low temperature. Can. J. Civ. Eng. 2004, 31, 239-252. [CrossRef]

72. You, Y.C.; Choi, K.S.; Kim, J. An experimental investigation on flexural behavior of RC beams strengthened with prestressed CFRP strips using a durable anchorage system. Compos. Part B Eng. 2012, 43, 3026-3036. [CrossRef]

73. Kotynia, R.; Michels, J.; Staśkiewicz, M.; Czaderski, C.; Motavalli, M. First application of prestressed CFRP laminates with gradient anchorage in strengthening post-tensioned concrete bride in Szczercowska Wieś. In Proceedings of the 10th Central European Congress on Concrete Engineering CCC 2014, Liberec, Czech Republic, 1-2 October 2014.

74. Correia, L.; Teixeira, T.; Michels, J.; Almeida, J.A.P.P.; Sena-Cruz, J. Flexural behaviour of RC slabs strengthened with prestressed CFRP strips using different anchorage systems. Compos. Part B Eng. 2015, 81, 158-170. [CrossRef]

75. Pellegrino, C.; Modena, C. Flexural strengthening of real-scale RC and PRC beams with end-anchored pretensioned FRP Laminates. ACI Struct. J. 2009, 106, 319-328.

76. Michels, J.; Staśkiewicz, M.; Czaderski, C.; Lasek, K.; Kotynia, R.; Motavalli, M. Anchorage resistance of CFRP strips externally bonded to various cementitious substrates. Compos. Part B Eng. 2014, 63, 50-60. [CrossRef]

77. Kim, Y.; Green, M.; Wight, G. Effect of prestress levels in prestressed CFRP laminates for strengthening prestressed concrete beams: A numerical parametric study. PCI J. 2010, 55, 96-108. [CrossRef]

78. Yu, P.; Silva, P.F.; Nanni, A. Flexural strength of reinforced concrete beams strengthened with prestressed carbon fiber-reinforced polymer sheets-Part II. ACI Struct. J. 2008, 105, 11-20. [CrossRef]

79. Schranz, B.; Michels, J.; Czaderski, C.; Shahverdi, M. Strengthening of concrete structures with iron-based shape memory alloy elements: Case studies. In Proceedings of the SMAR 2019: Fifth Conference on Smart Monitoring, Assessment and Rehabilitation of Civil Structures, Potsdam, Germany, 27-29 August 2019.

80. Basics of Direct Fastening Technology. Available online: https://ask.hilti.com/article/basics-of-direct-fastening-technology/97 3dw1/ (accessed on 22 November 2021).

81. Schranz, B.; Czaderski, C.; Shahverdi, M.; Michels, J.; Vogel, T.; Motavalli, M. Ribbed iron-based shape memory alloy bars for pre-stressed strengthening applications. In Proceedings of the IABSE Conference, Guimarães, Portugal, $27-29$ March 2019.

82. Rojob, H.; El-Hacha, R. New anchorage mechanism for smooth Fe-SMA bar used for flexural strengthening of RC beams using NSM technique. In Proceedings of the SMAR 2017: Fourth International Conference on Smart Monitoring, Assessment and Rehabilitation of Civil Structures, Zurich, Switzerland, 13-15 September 2017.

83. Maruyama, T.; Kubo, H. 12-Ferrous (Fe-based) shape memory alloys (SMAs): Properties, processing and applications. In Woodhead Publishing Series in Metals and Surface Engineering; Yamauchi, K., Ohkata, I., Tsuchiya, K., Miyazaki, S.B.T.-S.M., Eds.; Woodhead Publishing: Sawston, UK, 2011; pp. 141-159. ISBN 978-1-84569-707-5.

84. Triantafillou, T.; Mathys, S.; Audenaert, K.; Balazs, G.; Blaschko, M.; Blontrocki, H.; Czaderski, C.; David, E.; Di Tomaso, A.; Duckett, W.; et al. Fib Bulletin 14. Externally Bonded FRP Reinforcement for RC Structures; The International Federation for Structural Concrete: Lausanne, Switzerland, 2001; ISBN 978-2-88394-054-3. [CrossRef]

85. Goertzen, W.K.; Kessler, M.R. Creep behavior of carbon fiber/epoxy matrix composites. Mater. Sci. Eng. A 2006, 421, 217-225. [CrossRef]

86. American Concrete Institute. ACI 440.4R-04. In Prestressing Concrete Structures with FRP Tendons; American Concrete Institute: Farmington Hills, MI, USA, 2004.

87. Shang, S.; Zhang, B.; Wu, J. Long-term performance research on reinforced concreted beams with pre-stressed CFRP. Proc. Eng. 2010, 4, 341-346. [CrossRef]

88. Kim, Y.J.; Jung, W.-T.; Kang, J.-Y.; Park, J.-S. Testing methods and design specifications for CFRP-prestressed concrete members: A review of current practices and case studies. Case Stud. Constr. Mater. 2021, e00842. [CrossRef]

89. Sovják, R.; Havlásek, P.; Vítek, J. Long-term behavior of concrete slabs prestressed with CFRP rebars subjected to four-point bending. Constr. Build. Mater. 2018, 188, 781-792. [CrossRef]

90. Terrasi, G.P.; Meier, U.; Affolter, C. Long-term bending creep behavior of thin-walled CFRP tendon pretensioned spun concrete poles. Polymers 2014, 6, 2065-2081. [CrossRef]

91. Przygocka, M.; Kotynia, R. Pre-stress losses in frp pre-stressed reinforced concrete-Subject overview. Arch. Civ. Eng. 2018, 64, 257-268. [CrossRef]

92. Ghafoori, E.; Hosseini, E.; Leinenbach, C.; Michels, J.; Motavalli, M. Fatigue behavior of a Fe-Mn-Si shape memory alloy used for prestressed strengthening. Mater. Des. 2017, 133, 349-362. [CrossRef]

93. Vůjtěch, J.; Ryjáček, P.; Campos Matos, J.; Ghafoori, E. Iron-Based shape memory alloy for strengthening of 113-Year bridge. Eng. Struct. 2021, 248, 113231. [CrossRef]

94. Michels, J.; Shahverdi, M.; Czaderski, C.; El-Hacha, R. Mechanical performance of iron-based shape-memory alloy ribbed bars for concrete prestressing. ACI Mater. J. 2018, 115, 877-886. [CrossRef]

95. Hosseini, E.; Ghafoori, E.; Leinenbach, C.; Motavalli, M.; Holdsworth, S. Stress recovery and cyclic behaviour of an Fe-Mn-Si shape memory alloy after multiple thermal activation. Smart Mater. Struct. 2018, 27, 25009. [CrossRef]

96. Leinenbach, C.; Lee, W.J.; Lis, A.; Arabi-Hashemi, A.; Cayron, C.; Weber, B. Creep and stress relaxation of a FeMnSi-based shape memory alloy at low temperatures. Mater. Sci. Eng. A 2016, 677, 106-115. [CrossRef] 
97. Shahverdi, M.; Michels, J.; Czaderski, C.; Arabi-Hashemi, A.; Motavalli, M. Iron-based shape memory alloy strips, part 1: Characterization and material behavior. In Proceedings of the SMAR 2017: Fourth International Conference on Smart Monitoring, Assessment and Rehabilitation of Civil Structures, Zurich, Switzerland, 13-15 September 2017.

98. Meier, U. Strengthening of structures using carbon fibre/epoxy composites. Constr. Build. Mater. 1995, 9, 341-351. [CrossRef]

99. Kotynia, R.; Lasek, K. Efektywność zastosowania wstępnie naprężonych taśm CFRP do wzmacniania belek żelbetowych na zginanie. Badania Doświadczalne Elem. Konstr. Betonowych 2018, 1-168. [CrossRef]

100. Benmokrane, B.; Ali, D.-A.; Mohamed, H.; Robert, M.; ElSafty, A. Durability performance and service life of CFCC tendons exposed to elevated temperature and alkaline environment. J. Compos. Constr. 2015, 20, 4015043. [CrossRef]

101. Fernandes, P.; Sena-Cruz, J.; Xavier, J.; Silva, P.; Pereira, E.; Cruz, J. Durability of bond in NSM CFRP-concrete systems under different environmental conditions. Compos. Part B Eng. 2018, 138, 19-34. [CrossRef]

102. Lee, W.; Partovi-Nia, R.; Suter, T.; Leinenbach, C. Electrochemical characterization and corrosion behavior of an Fe-Mn-Si shape memory alloy in simulated concrete pore solutions. Mater. Corros. 2015, 67, 839-846. [CrossRef]

103. Hu, B.; Bai, P.; Dong, Z.; Cheng, J. Effect of Cu addition on corrosion resistance and shape memory effect of Fe- $14 \mathrm{Mn}-5 \mathrm{Si}-9 \mathrm{Cr}-5 \mathrm{Ni}$ alloy. Trans. Nonferrous Met. Soc. China 2009, 19, 149-153. [CrossRef]

104. Huang, X.; Chen, S.; Hsu, T.Y.; Zuyao, X. Corrosion behavior of Fe25Mn6Si5Cr shape memory alloys modified with rare earth in a $\mathrm{NaCl}$ solution. J. Mater. Sci. 2004, 39, 6857-6859. [CrossRef]

105. Della Rovere, C.A.; Alano, J.H.; Silva, R.; Nascente, P.A.P.; Otubo, J.; Kuri, S.E. Influence of alloying elements on the corrosion properties of shape memory stainless steels. Mater. Chem. Phys. 2012, 133, 668-673. [CrossRef]

106. Baroni, L.F.S.; Silva, R.; Vacchi, G.S.; Sordi, V.L.; Rovere, C.A.D. Influence of Ce on the corrosion properties of Fe-Mn-Si-based shape memory stainless steel. Mater. Today Commun. 2020, 25, 101649. [CrossRef]

107. Söderberg, O.; Liu, X.W.; Yakovenko, P.G.; Ullakko, K.; Lindroos, V.K. Corrosion behaviour of Fe-Mn-Si based shape memory steels trained by cold rolling. Mater. Sci. Eng. A 1999, 273-275, 543-548. [CrossRef]

108. Lin, H.C.; Lin, K.M.; Lin, C.S.; Ouyang, T.M. The corrosion behavior of Fe-based shape memory alloys. Corros. Sci. 2002, 44, 2013-2026. [CrossRef]

109. Dias, D.; Nakamatsu, S.; Della Rovere, C.; Otubo, J.; Mariano, N. Characterization and Corrosion Resistance Behavior of Shape Memory Stainless Steel Developed by Alternate Routes. Metals 2019, 10, 13. [CrossRef]

110. Joo, J.; Kang, M.; Shin, D.; Seo, E.; Kim, D.; Yeon, Y.; Hong, K.; Lee, W.; Lee, J. Corrosion resistance of shape recoverable Fe-17Mn-5Si-5Cr Alloy in concrete structures. Materials 2020, 13, 5531. [CrossRef]

111. Corrosion Protection of Building. Available online: https://www.re-fer.eu/en/re-plate-2/corrosion-protection/ (accessed on 22 November 2021).

112. Vaysburd, A.M.; Bissonnette, B.; von Fay, K.F. Compatibility Issues in Design and Implementation of Concrete Repairs and Overlays; Bureau of Reclamation, Technical Service Center: Denver, CO, USA, 2014; p. 136.

113. European Committee for Standardization. EN 1992-1-1:2004. Eurocode 2: Design of Concrete Structures-Part 1-1: General Rules and Rules for Buildings; CEN: Brussels, Belgium, 2004.

114. Fritsch, E.; Izadi, M.; Ghafoori, E. Development of nail-anchor strengthening system with iron-based shape memory alloy (Fe-SMA) strips. Constr. Build. Mater. 2019, 229, 117042. [CrossRef]

115. Aydin, F. Experimental investigation of thermal expansion and concrete strength effects on FRP bars behavior embedded in concrete. Constr. Build. Mater. 2018, 163, 1-8. [CrossRef]

116. Ghafoori, E.; Hosseini, A.; Al-Mahaidi, R.; Zhao, X.-L.; Motavalli, M. Prestressed CFRP-strengthening and long-term wireless monitoring of an old roadway metallic bridge. Eng. Struct. 2018, 176, 585-605. [CrossRef]

117. Hosseini, A.; Ghafoori, E.; Al-Mahaidi, R.; Zhao, X.-L.; Motavalli, M. Strengthening of a 19th-century roadway metallic bridge using nonprestressed bonded and prestressed unbonded CFRP plates. Constr. Build. Mater. 2019, 209, 240-259. [CrossRef]

118. Ghafoori, E.; Neuenschwander, M.; Shahverdi, M.; Czaderski, C.; Fontana, M. Elevated temperature behavior of an iron-based shape memory alloy used for prestressed strengthening of civil structures. Constr. Build. Mater. 2019, 211, 437-452. [CrossRef]

119. Neuenschwander, M.; Knobloch, M.; Fontana, M. Elevated temperature mechanical properties of solid section structural steel. Constr. Build. Mater. 2017, 149, 186-201. [CrossRef]

120. Yu, B.; Kodur, V. Effect of temperature on strength and stiffness properties of near-surface mounted FRP reinforcement. Compos. Part B Eng. 2014, 58, 510-517. [CrossRef]

121. Bisby, L.A.; Green, M.F.; Kodur, V.K.R. Response to fire of concrete structures that incorporate FRP. Prog. Struct. Eng. Mater. 2005, 7, 136-149. [CrossRef]

122. Firmo, J.P.; Correia, J.R.; Bisby, L.A. Fire behaviour of FRP-strengthened reinforced concrete structural elements: A state-of-the-art review. Compos. Part B Eng. 2015, 80, 198-216. [CrossRef]

123. Wang, Y.C.; Wong, P.M.H.; Kodur, V. An experimental study of the mechanical properties of fibre reinforced polymer (FRP) and steel reinforcing bars at elevated temperatures. Compos. Struct. 2007, 80, 131-140. [CrossRef]

124. Wang, K.; Young, B.; Smith, S.T. Mechanical properties of pultruded carbon fibre-reinforced polymer (CFRP) plates at elevated temperatures. Eng. Struct. 2011, 33, 2154-2161. [CrossRef]

125. Bisby, L.A. Fire Behaviour of Fibre-Reinforced Polymer (FRP) Reinforced or Confined Concrete. Ph.D. Thesis, Queen's University, Kingston, ON, Canada, 2003. 
126. Carlos, T.B.; Rodrigues, J.P.C.; de Lima, R.C.A.; Dhima, D. Experimental analysis on flexural behaviour of RC beams strengthened with CFRP laminates and under fire conditions. Compos. Struct. 2018, 189, 516-528. [CrossRef]

127. Azevedo, A.S.; Firmo, J.P.; Correia, J.R.; Chastre, C.; Biscaia, H.; Franco, N. Fire behaviour of CFRP-strengthened RC slabs using different techniques-EBR, NSM and CREatE. Compos. Part B Eng. 2021, 109471. [CrossRef]

128. Rojob, H.; El-Hacha, R. Ductility behavior of RC beams strengthened in flexure with NSM iron-based shape memory alloy bars. In Proceedings of the SMAR 2015: Third Conference on Smart Monitoring, Assessment and Rehabilitation of Civil Structures, Antalya, Turkey, 7-9 September 2015.

129. Shahverdi, M.; Motavalli, M.; Abouali, S.; Ghassemieh, M. Nonlinear simulation of reinforced concrete beams retrofitted by near-surface mounted iron-based shape memory alloys. Eng. Struct. 2019, 187, 133-148. [CrossRef]

130. Raad, J.; Parvin, A. Iron-based shape memory alloy and fiber reinforced polymers rods for prestressed NSM strengthening of RC beams. Eng. Struct. 2020, 207, 110274. [CrossRef]

131. Rojob, H.; El-Hacha, R. Prestressed FRP for flexural strengthening of large-scale RC beams versus self-prestressing SMAA comparison. In Proceedings of the 8th International Conference on Fibre-Reinforced Polymer (FRP) Composites in Civil Engineering CICE 2016, Hong Kong, China, 14-16 December 2016.

132. Rojob, H.; El-Hacha, R. Numerical investigation of the flexural performance of RC beam strengthened with iron-based shape memory alloys bar. In Proceedings of the 27th Biennial National Conference of the Concrete Institute of Australia in conjunction with the 69th RILEM Week. Concrete 2015, Melbourne, Australia, 2 September 2015.

133. El-Hacha, R.; Rojob, H. Fatigue performance of RC beams strengthened in flexure using NSM iron-based shape memory alloy bars. In Proceedings of the Third Conference on Smart Monitoring, Assessment and Rehabilitation of Civil Structures, Antalya, Turkey, 7-9 September 2015.

134. Rojob, H.; El-Hacha, R. Performance of RC beams strengthened with self-prestressed Fe-SMA bars exposed to freeze-thaw cycles and sustained load. Eng. Struct. 2018, 169, 107-118. [CrossRef]

135. Abouali, S.; Shahverdi, M.; Ghassemieh, M.; Motavalli, M. Assessment of flexural strengthening of RC beams with iron-based shape memory alloys. In Proceedings of the 11th International Congress on Civil Engineering, Tehran, Iran, 8-10 May 2018.

136. Strieder, E.; Aigner, C.; Petautschnig, G.; Horn, S.; Marcon, M.; Schwenn, M.; Zeman, O.; Castillo Ruano, P.; Wan-Wendner, R.; Bergmeister, K. Strengthening of Reinforced Concrete Beams with Externally Mounted Sequentially Activated Iron-Based Shape Memory Alloys. Materials 2019, 12, 345. [CrossRef]

137. Dolatabadi, N.; Shahverdi, M.; Ghassemieh, M.; Motavalli, M. RC Structures strengthened by an iron-based shape memory alloy embedded in a shotcrete layer-Nonlinear finite element modeling. Materials 2020, 13, 5504. [CrossRef]

138. Mostakhdemin Hosseini, M.R.; Dias, S.J.E.; Barros, J.A.O. Flexural strengthening of reinforced low strength concrete slabs using prestressed NSM CFRP laminates. Compos. Part B Eng. 2016, 90, 14-29. [CrossRef]

139. Peng, H.; Zhang, J.; Cai, C.S.; Liu, Y. An experimental study on reinforced concrete beams strengthened with prestressed near surface mounted CFRP strips. Eng. Struct. 2014, 79, 222-233. [CrossRef]

140. Lee, H.; Jung, W.T.; Chung, W. Post-tension near-surface mounted strengthening system for reinforced concrete beams with changes in concrete condition. Compos. Part B Eng. 2019, 161, 514-529. [CrossRef]

141. Piatek, B.; Siwowski, T. Experimental study on flexural behaviour of reinforced concrete beams strengthened with passive and active CFRP strips using a novel anchorage system. Arch. Civ. Mech. Eng. 2022, 22, 45. [CrossRef]

142. Brühwiler, E.; Menn, C. Vorspannung ohne verbund. In Stahlbetonbrücken; Springer: Wien, Austria, 2003; pp. 216-219. ISBN 978-3-7091-7261-2.

143. Lee, H.; Jung, W.T.; Chung, W. Field test of an old RC bridge before and after NSM strengthening. Compos. Struct. 2018, 202, 793-801. [CrossRef] 